OPEN ACCESS

Edited by:

Alexander Bartelt,

Ludwig Maximilian University

of Munich, Germany

Reviewed by:

Hsien-Hui Chung,

National Cheng Kung University,

Taiwan

Joerg Heeren

University Medical Center

Hamburg-Eppendorf, Germany

*Correspondence:

Guadalupe Sabio

gsabio@cnic.es

Ivana Nikolic

inikolic@cnic.es

Specialty section: This article was submitted to Experimental Endocrinology,

a section of the journal

Frontiers in Endocrinology

Received: 12 June 2020 Accepted: 17 November 2020 Published: 23 December 2020

Citation:

Leiva M, Matesanz N,

Pulgarín-Alfaro M, Nikolic I

and Sabio G (2020) Uncovering the

Role of p38 Family Members in

Adipose Tissue Physiology.

Front. Endocrinol. 11:572089.

doi: 10.3389/fendo.2020.572089

\section{Uncovering the Role of p38 Family Members in Adipose Tissue Physiology}

\author{
Magdalena Leiva, Nuria Matesanz, Marta Pulgarín-Alfaro, Ivana Nikolic * \\ and Guadalupe Sabio *
}

Centro Nacional de Investigaciones Cardiovasculares (CNIC), Madrid, Spain

The complex functions of adipose tissue have been a focus of research interest over the past twenty years. Adipose tissue is not only the main energy storage depot, but also one of the largest endocrine organs in the body and carries out crucial metabolic functions. Moreover, brown and beige adipose depots are major sites of energy expenditure through the activation of adaptive, non-shivering thermogenesis. In recent years, numerous signaling molecules and pathways have emerged as critical regulators of adipose tissue, in both homeostasis and obesity-related disease. Among the best characterized are members of the p38 kinase family. The activity of these kinases has emerged as a key contributor to the biology of the white and brown adipose tissues, and their modulation could provide new therapeutic approaches against obesity. Here, we give an overview of the roles of the distinct p38 family members in adipose tissue, focusing on their actions in adipogenesis, thermogenic activity, and secretory function.

Keywords: signaling, kinase, Adipose, Brown, P38, p38 mitogen-activated protein kinase(s)

\section{INTRODUCTION}

Obesity has become a global pandemic, in part due to lifestyle changes that have brought about an imbalance between energy intake and expenditure. Obesity is characterized by the expansion of adipose tissue through both the hypertrophy of preexisting adipocytes and hyperplasia of adipocyte precursors (1). Adipose tissue has a unique capacity to expand and retract depending on the energy demands (2). This plasticity, unparalleled in other organs, makes adipose tissue the main lipid storage organ. For many years, this was thought to be its only function. However, today adipose tissue is recognized as an indispensable, multi-faceted, and highly metabolically active organ that fulfils a range of functions including mechanical protection and thermal insulation, energy storage, immune responses, endocrine functions, and non-shivering thermogenesis (3). These advances in adipose tissue biology situate the adipocyte as a central rheostat in the regulation of systemic nutrient and energy homeostasis (4).

Stress activated protein kinases (SAPKs) are an important family of mitogen activated protein kinases (MAPKs) that are activated by stress stimuli in a cell-type-dependent manner and transduce stress signals into the cell $(5,6)$. The SAPKs include the JNK family (JNK1, JNK2, and JNK3) and the $\mathrm{p} 38$ family, which numbers four members: $\mathrm{p} 38 \alpha, \mathrm{p} 38 \beta, \mathrm{p} 38 \gamma$, and $\mathrm{p} 38 \delta$. SAPKs in adipose tissue of obese individuals have been recognized as important contributors to obesity development and 
associated insulin resistance. Obesity triggers JNK activation in adipose tissue, where it plays an essential role in adipocytemediated insulin resistance $(7,8)$. In contrast, p38 $\alpha$ activity is markedly decreased in the adipose tissue of mice with dietinduced or genetically induced (ob/ob) obesity (9). This finding is borne out by low $\mathrm{p} 38 \alpha$ expression in human adipose tissue from obese individuals, with the level of this kinase correlating inversely with body mass index (BMI) (10). However, several upstream kinases are upregulated in visceral fat from overweight and obese individuals, including ASK1 and MKK6 (11, 12), suggesting that other p38 isoforms might be activated in these conditions.

p38 pathway is one of the main proposed controllers of the activation of brown adipose tissue (BAT) and the browning of white adipose tissue (WAT). In both processes, p38 signaling operates by inducing uncoupling protein 1 (UCP1) transcription through the activation of cAMP response element-binding protein (CREB), activating transcription factor 2 (ATF2), and peroxisome proliferator-activated receptor gamma coactivator $1 \alpha(\mathrm{PGC} 1 \alpha)(13)$. WAT browning and BAT activation are thought to require activation of the p38 cascade by $\beta$ adrenergic stimuli or other browning agents (13-22). However, it remains unclear what roles are played in these processes by each of the p38 family members, which have distinct physiological functions and expression patterns. It is therefore vital to determine the precise regulation of this pathway and to identify which p38 and upstream kinases are implicated in WAT browning and BAT activation. Recent results obtained in our laboratory indicate that the activation of each p38 is tissue- and upstream-kinase-dependent. For example, all p38s in WAT are activated mostly by MKK3, and mice lacking this kinase show a robust decrease in p38 activation; however, we recently showed that in BAT, p38 activation is mainly dependent on MKK6 (12). Interestingly, in obesity, MKK6 expression increases in WAT but decreases in BAT. These data suggest that $\mathrm{p} 38$ regulation differs markedly between BAT and WAT.

\section{THE P38 MAPK PATHWAY AND ADIPOGENESIS}

Knowledge about the origin of white and brown adipocytes has been substantially revised in the last few years. Although brown and white adipocytes share a mesodermal origin, they originate from different populations of embryonic multipotent mesenchymal stem cells (MSCs) $(23,24)$. Due to its function in thermogenesis, especially in newborns, BAT develops before birth, and brown adipocytes originate from the myogenic Myf5positive MSC lineage (25). White preadipocytes arise from adipogenic Myf5-negative MSCs and differentiate to WAT shortly after birth $(26,27)$. Despite this difference in MSC origin, adipogenesis in both white and brown adipocytes involves the activation of the same key transcription factors: peroxisome proliferator-activated receptor $\gamma(\operatorname{PPAR} \gamma)$ and CCAAT/enhancer-binding proteins $(\mathrm{C} / \mathrm{EBP})(28,29)$. Adipocyte differentiation is also regulated by bone morphogenetic proteins
(BMP), members of the transforming growth factor (TGF)- $\beta$ superfamily. Differentiation of white adipocytes is regulated by BMPs 2 and 4 (30-32), whereas BMP7 and PR domain containing 16 (PRDM16) are crucial factors in the differentiation of preadipocytes to mature brown adipocytes $(17,33)$. Another common regulator of brown and white adipocyte differentiation is the p38 pathway, and here we will summarize the current knowledge about the role of this kinase family in WAT and BAT adipogenesis.

\section{p38 Protein Kinase Family Controls White Adipogenesis}

The precise role of p38 kinases in adipogenesis remains unclear, with some studies indicating that p38 activation promotes adipogenesis (34-36) while others suggesting that it inhibits this process $(9,37,38)$. More than two decades ago, pioneering work by Engelman and colleagues demonstrated that p38 orchestrates the early steps in the differentiation of 3T3-L1 fibroblasts to adipocytes by activating the transcription factor $\mathrm{C} / \mathrm{EBP} \beta$. These authors found that pharmacological inhibition of p38 blocked the initial stages of adipogenesis but did not affect the later stages of differentiation (34). Work by the same group also demonstrated the important contribution of p38 to adipogenesis and the consequent need to tightly regulate its activity during this process. This work showed that p38 activation, by salicylate or active MKK6, spontaneously triggers adipogenesis of 3T3-L1 cells and that uncontrolled and prolonged activation of p38 results in massive cell death (36). Nevertheless, other studies have demonstrated a negative role of p38 in adipogenesis (39). p38 phosphorylates the C/EBP homologous protein (CHOP), a negative regulator of $\mathrm{C} / \mathrm{EBP} \alpha$ (38), and nuclear factor of activated T cells 4 (NFATc4) (37), both of which regulate adipocyte differentiation. In addition, Aouadi and colleagues found that p38 activity declines during adipocyte differentiation and that pharmacological or genetic p38 $\alpha$ deficiency stimulates adipogenesis in vitro and in vivo. The anti-adipogenic effects of p38 are due to inhibition of $\mathrm{C} / \mathrm{EBP} \beta$ and PPAR $\gamma$ activity (9). Contrasting the mouse results, the same authors demonstrated a positive role of p38 in human preadipocyte differentiation, showing that pharmacological inhibition of $\mathrm{p} 38$ reduced $\mathrm{C} / \mathrm{EBP} \beta$ phosphorylation, $\operatorname{PPAR} \gamma$ expression, and lipid accumulation in primary human preadipocytes (35).

To evaluate the alteration of nuclear proteins during early stages of 3T3-L1 preadipocyte differentiation, Rabiee et al. performed a proteomic and phosphoproteomic analysis. After generating a kinase-substrate database, these authors showed that most putative protein kinases involved in early adipogenesis belong to the cyclin-dependent kinase (CDK) family and the MAPK family, which includes p38 and JNK (40). Further analysis showed that most transcriptional regulators are phosphorylated during early adipogenesis and that most of the phosphorylated peptides included the consensus motif $S(p) / T$ (p)-P. These are target sequences for CDKs and MAPKs, thus establishing the fundamental role of MAPKs in adipogenesis. Interestingly, we recently demonstrated that $\mathrm{p} 38 \gamma$ and $\mathrm{p} 38 \delta$ can 
act as CDKs and that the CDK and p38 kinase families cooperate in the phosphorylation of their substrates in the liver (41). It would be interesting to assess whether these kinase families also jointly coordinate the differentiation of adipose tissue.

The transcription factor BMP4 plays an important role in white adipocyte development by triggering MSC commitment to adipocyte fate $(42,43)$, inhibiting the brown phenotype during terminal differentiation, and promoting a shift from the brown adipocyte phenotype towards a white-like phenotype (32). BMP4 and the related BMP2 mediate adipogenic function via two main signaling pathways: the canonical SMAD pathway (44) and a SMAD-independent pathway that involves activation of p38 by the upstream activators transforming growth factor betaactivated kinase 1 (TAK1), MKK3, and MKK6 (45). BMP2induced p38 activation (45) leads to the phosphorylation of its downstream substrate ATF2, which in turn regulates PPAR $\gamma 2$ expression and adipogenesis (Figure 1). In consequence, ATF2 deletion or the chemical inhibition of $\mathrm{p} 38 \alpha / \beta$ in mice results in decreased PPAR $\gamma 2$ expression and adipocyte differentiation in vitro. The reduced WAT content in these mice protects them against high fat diet (HFD)-induced obesity (46). In addition to these mechanisms, BMP4-induced activation of SMAD and p38s was recently shown to induce focal adhesion kinase (FAK) in early adipogenesis, and FAK silencing or inhibition downregulated adipogenesis while also reducing SMAD and p38 activation (47). These findings suggest that there are more molecular players in these complex processes yet to be discovered (Figure 1).

p38 signaling is also implicated in the adipogenic action of monocyte chemotactic protein 1 (MCP1)-induced protein
(MCPIC). MCP1 and its receptor CCR2 are produced in preadipocytes during in vitro adipogenesis and contribute to adipogenesis through the induction of MCPIP (48). During the later stages of adipogenesis, MCPIP triggers the endoplasmic reticulum stress response, autophagy, ROS induction, and p38 activation. Chemical inhibition of p38 in 3T3-L1 cells attenuates the expression of adipogenic markers (adiponectin and lipoprotein lipase) in MCPIP-induced adipogenesis (49), suggesting a pro-adipogenic role of the p38 family (Figure 1).

\section{p38 SAPKs As Regulators of Brown Adipogenesis}

Significant progress has also been made in understanding the molecular mechanisms of brown adipogenesis. BMP2 and BMP4 have been reported to promote white adipogenesis in MSCs or preadipocytes in vitro when exposed to an adipogenic cocktail (50, 51); however, Tseng et al. showed that in the absence of the adipogenic cocktail, treatment with BMP2, BMP4, BMP6, or BMP7 promotes lipid accumulation in brown but not white preadipocytes (17). Of these BMPs, BMP7 is the only one that substantially increases the expression of UCP1, other early brownfat fate regulators like PRDM16 and PGC1 $\alpha$, and the adipogenic transcription factors PPAR $\gamma$ and C/EBPs, as well as inducing mitochondrial biogenesis (17). The same study also established that BMP7-induced brown adipogenesis requires 338 and PGC1 $\alpha$ : BMP7 treatment of brown preadipocytes activated p38, leading to phosphorylation of its substrate ATF2 (Figure 2), whereas p38 inhibition reduced BMP-7-induced UCP1 expression (17). A recent comparative epigenome and transcriptome profiling of $\mathrm{C} 3 \mathrm{H} 10 \mathrm{~T} 1 / 2$ mesenchymal cells during differentiation into thermogenic brown

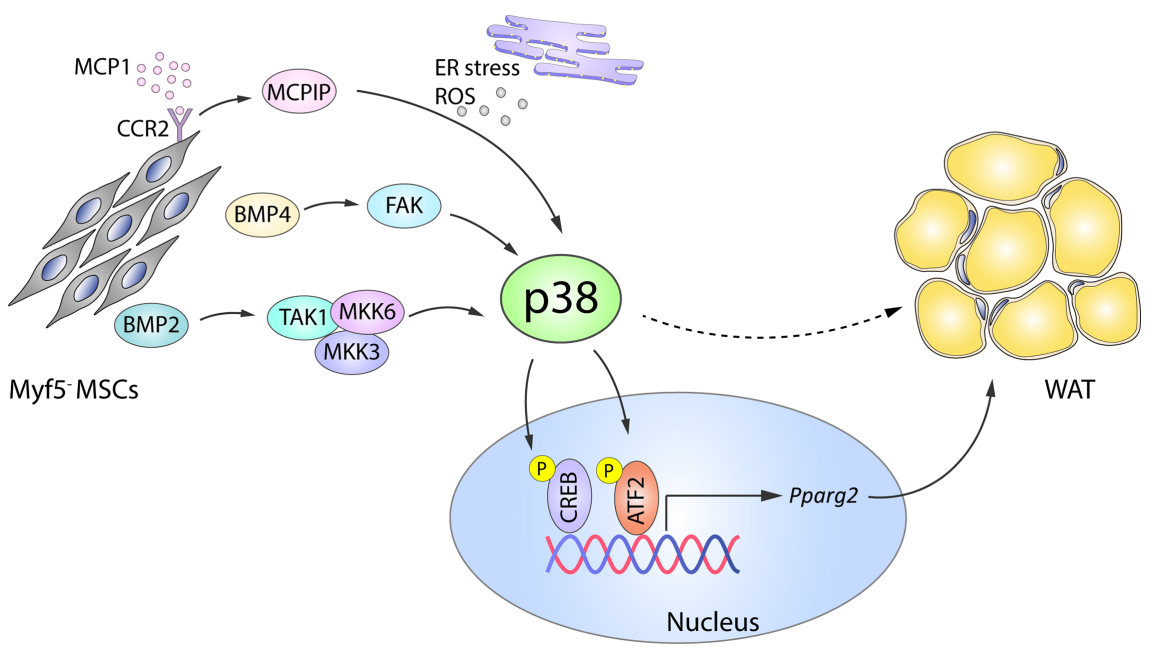

FIGURE 1 | Role of p38 in WAT adipogenesis. In Myf5- MSC cells, p38 protein kinase family members are activated by a variety of upstream activators, including BMP2-TAK1-MKK3/6, BMP4-FAK, and MCP1-MCPIP. p38-mediated phosphorylation and activation of CREB and ATF2 then leads to increased expression of Pparg2 and WAT adipogenesis. Solid arrows represent the direct effects of molecular players involved in the indicated signaling pathways, while dotted arrows represent indirect effects, meaning that other unknown molecules might be involved. ATF2, activating transcription factor 2;BMP, bone morphogenetic proteins; CREB, cAMP response element-binding; ER, endoplasmic reticulum; FAK, focal adhesion kinase; MCP1, monocyte chemotactic protein 1; MCPIP, MCP1-induced protein; MKK, mitogen-activated protein kinase kinase; ROS, reactive oxygen species; MSC, mesenchymal stem cell; Pparg2, peroxisome proliferator-activated receptor gamma 2; TAK1, transforming growth factor beta-activated kinase 1; WAT, white adipose tissue. Yellow circled 'P' indicates phosphorylation. 


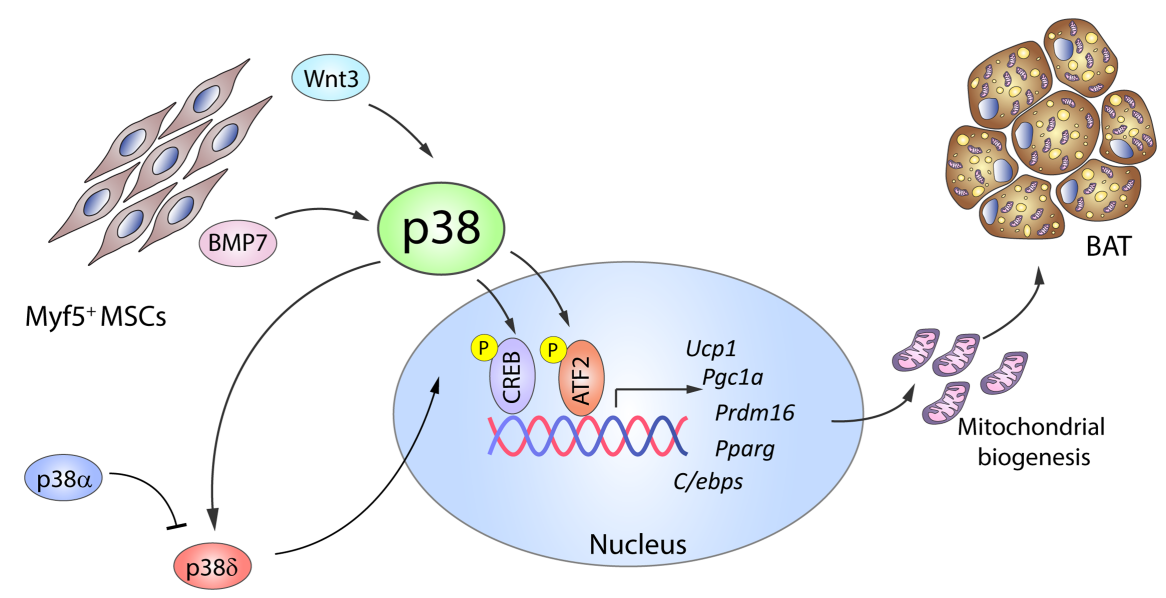

FIGURE 2 | The p38 kinase family controls BAT adipogenesis. Brown adipocytes originate from Myf5 ${ }^{+}$MSC cells. BMP7 and Wnt3 activate p38 protein kinases, which phosphorylate and activate CREB and ATF2, leading to increased gene expression of brown adipocyte signature markers and mitochondrial biogenesis. p38 $\delta$ has been suggested as the main kinase promoting BAT activation, whereas p38 $\alpha$ has opposing effects. Black arrows represent the direct effects of molecular players involved in the indicated signaling pathways or effects. ATF2, activating transcription factor 2; BAT, brown adipose tissue; BMP, bone morphogenetic protein; C/ebp, CCAAT/enhancer-binding protein; CREB, cAMP response element-binding; MSC, mesenchymal stem cell; Ppargc1a, peroxisome proliferator-activated receptor gamma coactivator $1 \alpha$, Prdm16, PR domain containing 16; Pparg, peroxisome proliferator-activated receptor; Ucp1, uncoupling protein 1. Yellow circled 'P' indicates phosphorylation.

adipocytes revealed that BMP7-p38 signaling potentially targets Sox genes, which are important for early lineage commitment of multipotent progenitors to brown adipocytes (52). This study confirmed that Sox13 promotes adipogenic differentiation, brown marker gene expression, and mitochondrial respiration (52).

p38-CREB-mediated mitochondrial biogenesis is also promoted by the adipogenesis regulator Wnt3a. Treatment of in vitro differentiated 3T3-L1 adipocytes with Wnt3a upregulates the expression of mitochondrial genes and mitochondrial copy number in a process independent of the canonical Wnt/ $\beta$ catenin pathway (53). Instead, Wnt3a induces rapid and transient activation of p38 (54,55), and pharmacological inhibition of p38 reduces CREB activation and attenuates the observed effects of Wnt3a (Figure 2).

A number of naturally occurring compounds with pro- or antiadipogenic effects on white and brown adipogenesis have been found to act mainly through the AMPK $\alpha$ and p38 pathways. These compounds include phloretin (56), sinigrin (57), and cryptotanshione (58). Phloretin is a glucose transporter inhibitor found in some fruits that enhances adipogenesis in the bonemarrow derived stromal cell line ST2 by inhibiting ERK and JNK and activating p38 (56). Singirin, a glucoside found in broccoli, Brussels sprouts and black mustard seeds, has the opposite effect, inhibiting the early stage adipogenesis of 3T3-L1 adipocytes by activating AMPK, MAPKs, and acetyl-CoA carboxylase (57). Cryptotanshione, found in Salvia miltiorrhiza, stimulates brown adipogenesis and inhibits WAT-specific markers through AMPK $\alpha$, p38 $\alpha$, and SMAD signaling (58).

\section{Adipocyte Plasticity and Transdifferentiation}

Adipocyte-like cells can also be generated by the transdifferentiation of muscle satellite cells $(59,60)$, and this complex reprograming process is reversible (61). p38 kinases are candidate negative regulators of the broad molecular network involved. The p38 pathway is activated in early and late stages of transdifferentiation, and pharmacological inhibition of $\mathrm{p} 38 \alpha / \beta$ by SB203580 stimulates adipogenic metabolism, increases lipid production, and promotes expression of adipogenic regulators (62). In addition, dominantnegative MKK3 stimulates transdifferentiation of $\mathrm{C} 2 \mathrm{C} 12$ myogenic cells into adipocytes via upregulation of PPAR $\gamma$ and the phosphoinositide-3 kinase pathway (59). Furthermore, during pregnancy and lactation subcutaneous white adipocytes can also transdifferentiate into mammary glands and so-called pink adipocytes, responsible for milk production $(63,64)$ and this process is reversible after lactation (65). As discussed in this review, p38 protein kinase family has an important role in adipose tissue plasticity, and it would be interesting to examine the role of p38s in development and function of pink adipocytes.

Until recently, most evidence implicating p38 kinases in adipogenesis came from experiments with pharmacological inhibitors. However, kinase inhibitors have important limitations due to their lack of specificity and possible side effects. Using adipose p38 $\alpha$ knock out mice, we recently showed that lack of p38 $\alpha$ results in reduced weight of several fat depots, suggesting a possible positive role of $\mathrm{p} 38 \alpha$ in adipogenesis in vivo (10). These results were subsequently confirmed by another study (66). We also demonstrated that deletion of $\mathrm{p} 38 \alpha$ in adipose tissue leads to a reduced content of BAT and several types of WAT, whereas the lack of $\mathrm{p} 38 \delta$ has opposing effects (10). Moreover, in vitro-differentiated brown preadipocytes lacking $\mathrm{p} 38 \alpha$ have higher expression of brown adipocyte markers and mitochondrial genes, whereas lack of p38 $\delta$ downregulates BAT signature genes in differentiated brown adipocytes (10). These data highlight a novel role of $\mathrm{p} 38 \delta$ as a 
positive inducer of brown adipogenesis. The opposite roles of p $38 \alpha$ and $\mathrm{p} 38 \delta$ in brown adipogenesis underline the need for further research using genetically modified mice to define the actions of individual p38 family members in adipogenesis, both in early and late stages.

\section{P38 IN BAT ACTIVATION}

BAT is an important organ involved in fat burning and bodytemperature maintenance through non-shivering thermogenesis (67). Although the presence of BAT in small mammals and human newborns was well established, it was believed to lose its function in adult humans. A decade ago, positron emission computed tomography studies revealed certain areas of the adult human body with a very active uptake of fluorodeoxyglucose (68). These regions were identified as BAT depots, and are mainly located in cervical, supraclavicular, axillary, and paravertebral regions (69). The amount and the activity of BAT are dependent on several factors, such as age, leanness, and environmental temperature, and obese individuals have deficiencies in BAT activation and browning (68).

Mice with increased BAT activity are resistant to metabolic diseases, not only because they expend more energy on thermogenesis, but also because of improvements in systemic metabolism resulting from BAT actively removing glucose and lipids from the bloodstream and thereby increasing glucose tolerance and insulin sensitivity (69). This evidence suggests that modulation of BAT activity offers a possible therapeutic strategy for increasing energy expenditure and to achieving a negative energy balance, as well as an improved metabolic status.

\section{p38 Signaling During BAT Activation}

Whereas white adipocytes store lipids in a single large triglyceride-filled droplet and contain few mitochondria, brown adipocytes store lipids in multiple small droplets and contain a large number of mitochondria (67). In BAT, thermogenesis is mainly controlled by UCP1, a mitochondrial protein that uncouples the respiratory chain from ATP synthesis, so that the energy generated is dissipated as heat (13). BAT is activated by a variety of stimuli, including cold, hormones, and certain food components, all of which trigger an increase in proton flux through UCP1, resulting in heat production (70). BAT activation triggers a cell signal transduction that causes not only acute effects such as enhanced lipolysis and UCP1 activity, but also chronic effects that include increased expression of thermogenic genes, mitochondrial biogenesis, and neoplastic and hyperplasic growth of brown adipocytes $(67,71)$.

One of the key signaling proteins involved in BAT activation is protein kinase A (PKA). Activated PKA phosphorylates hormone sensitive lipase (HSL), stimulating its activity and in turn promoting lipolysis. The resulting free fatty acids (FFA) undergo $\beta$-oxidation, and the increase in FFA levels also promotes UCP1 activity (72-74). Additionally, PKA participates in the activation of the p38 pathway (15), which contributes to BAT thermogenesis through the phosphorylation of key transcription factors driving UCP1 expression $(12-14,17,18)$. Three well-recognized transcription factors within this group are $\mathrm{PGC} 1 \alpha, \mathrm{ATF} 2$ and CREB. $\mathrm{PGC} 1 \alpha$ is an important regulator of mitochondrial biogenesis and oxidative phosphorylation $(75,76)$ and is also required for enhanced UCP1 expression. p38 promotes PGC1 $\alpha$ transcription by phosphorylating ATF2 and CREB, which bind as homodimers to cAMP response elements (CREs) in the PGC1 $\alpha$ promoter $(13,77)$. CREB activation was thought to be p38 independent because PKA can promote its activation by direct phosphorylation at Ser133 $(13,15)$. However, CREB can be also an indirect target of p38 through activation of the p38 substrate MSK1 (78). Moreover, p38 also directly phosphorylates PGC1 $\alpha$, enhancing its stability and activity (79). Phosphorylated PGC1 $\alpha$ acts as a co-activator by interacting with different dimer combinations of $\operatorname{PPAR} \alpha, \operatorname{PPAR} \gamma$, retinoid X receptor, retinoic acid receptor, and thyroid receptor transcription factors $(19,71,80)$. These complexes bind to PPAR response elements present in both the PGC1 $\alpha$ and the UCP1 promoter, and PGC1 $\alpha$ thus acts as a coactivator not only for its own transcription in an autoregulatory loop, but also for UCP1 transcription (81). p38-mediated phosphorylation of ATF2 and CREB also allows these transcription factors to bind to CRE sites in the UCP1 promoter, increasing UCP1 expression (13). In light of this accumulated evidence, it seems undeniable that the $\mathrm{p} 38$ pathway plays a central role in the coordinated thermogenic response (Figure 3 ).

Recent research has identified another mechanism of p38mediated UCP1 regulation. p38-mediated phosphorylation of the transcription factor $\mathrm{Zc} 3 \mathrm{~h} 10$ at $\mathrm{S} 126$ induces its binding to the UCP1 promoter at a $\sim 4.6 \mathrm{~kb}$ upstream region, increasing UCP1 expression and thermogenesis (82).

\section{Signaling Triggering BAT Thermogenesis Through p38}

Cold-induced BAT activation and thermogenesis mainly relies on sympathetic nervous system (SNS) innervation. Upon cold exposure, catecholamines released by the SNS activate the thermogenic program in brown adipocytes by stimulating $\beta_{3^{-}}$ adrenergic receptors ( $\beta 3 \mathrm{AR})$ (68), which are abundantly expressed in this cell type. $\beta 3 \mathrm{AR}$ stimulation is followed by an adenylate cyclase (AC)-mediated increase in intracellular cAMP. The resulting activation of PKA is associated with increased expression of thermogenic genes via p38 activation (Figure 3).

BAT activity is also promoted by other factors, secreted either BAT or other organs. Thyroid hormones (TH) activate BAT by both TH-mediated SNS stimulation and peripheral actions (83). In brown adipocytes, $\mathrm{T} 4$ is converted by 5 -deiodinase type 2 (Dio2) to $\mathrm{T} 3$, which binds to $\mathrm{TH}$ receptors located in $\mathrm{TH}$ response elements (TREs) present in the promoters of thermogenic genes such as UCP1 (84). T3 thus acts synergistically with $\beta 3$-agonists to induce BAT activity. T3 also promotes fatty acid-oxidation, lipogenesis, and mitochondrial biogenesis in BAT (83), enhancing its thermogenic capacity. Although the main effects of T3 on BAT activation do not seem to rely on p38 signaling, our group demonstrated that p38 pathway mediates T3-induced browning in WAT (see below) (12). 


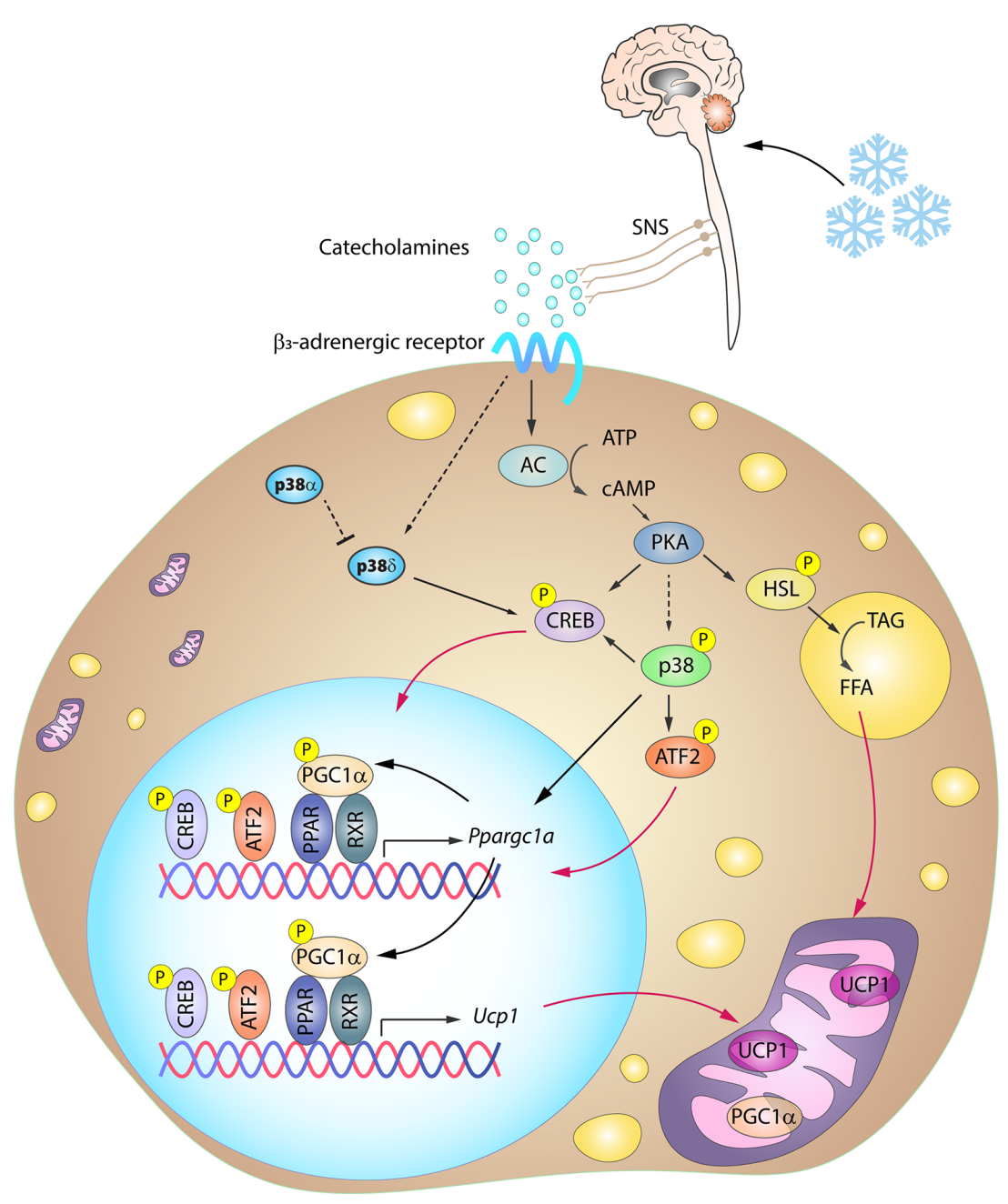

FIGURE 3 | Simplified scheme of the signaling cascade for BAT activation in response to cold. Cold-induced release of catecholamines by the SNS activates thermogenesis in brown adipocytes by stimulating $\beta 3$-adrenergic receptors, which trigger PKA activation through an increase in intracellular cAMP. PKA participates in the activation of several transcription factors involved in the BAT thermogenic response. p38-mediated phosphorylation of several of these transcription factors is necessary for the expression of BAT signature genes. Solid arrows represent the direct effects of molecular players involved in the indicated signaling pathways, dotted arrows represent indirect effects, meaning that other unknown molecules might be involved, while red arrows represent translocation between cell compartments. AC, adenylyl cyclase; ATF2, activating transcription factor 2; CAMP, cyclic AMP; CREB, CAMP response element-binding; HSL, hormone sensitive lipase; PGC1 $\alpha /$ Ppargc1a, peroxisome proliferator-activated receptor gamma coactivator $1 \alpha$; PKA, protein kinase A; PPAR, peroxisome proliferator-activated receptor; RXR, retinoid X receptor; SNS, sympathetic nervous system; TAG, triglycerides; UCP1, uncoupling protein 1. Yellow circled ' $P$ ' indicates phosphorylation.

In addition to their role in BAT differentiation, BMPs also regulate BAT activation. The canonical BMP signaling pathway depends on BMP binding to type I and II BMP receptors, which triggers activation of the SMAD pathway. However, non-canonical BMP signaling also activates the ERK, JNK, and p38 pathways (85). BMP8B is particularly important in the context of BAT activation. Whittle et al. demonstrated that BMP8B expression is upregulated in BAT after cold exposure or HFD, enhancing the response to adrenergic stimulation by increasing $\mathrm{p} 38$-CREB signaling and HSL activity. In that study, the authors showed that $B m p 8 b^{-1-}$ mice exhibit impaired thermogenesis and have a higher susceptibility to diet-induced obesity, together with decreased activation of p38CREB signaling. However, phosphorylation of the p38 upstream kinases MKK3 and MKK6 is increased, suggesting that BMP8B deletion leads to a blockade at this point in the signaling cascade (18).

A parallel pathway that seems to operate in synergy with $\beta_{3^{-}}$ adrenergic activation is mediated by natriuretic peptides (NPs). NPs are hormones secreted by the heart that bind to NP receptor A (NPRA), leading to an increase in cGMP and subsequent PKG activation, which in turn enhances UCP1 expression in BAT and other mitochondrial markers via p38 (86). However, the vast majority of studies related to the role of NPs in thermogenesis have been carried out in the context of browning.

Since BAT activation has emerged as a potential therapeutic approach for the treatment of obesity and other related diseases, immense efforts are currently directed towards finding new compounds able to activate BAT thermogenesis and browning. 
A number of compounds have been already identified, including menthol, capsaicin, and resveratrol (87-89). Ravaud et al. showed that the p38 pathway is required for resveratrolinduced UCP1 expression, whereas the HIV-protease inhibitor lopinavir has an opposing action associated with reduced p38 phosphorylation (90). Sinapic acid, a natural alkaloidal amine found in black mustard seeds, wine, and vinegar, was recently shown to promote thermogenesis and lipolysis in BAT via PKAp38 signaling (91). However, further studies are needed to provide greater insight into the potential involvement of the p38 pathway in the induction of BAT thermogenesis via these compounds.

\section{Function of p38s in BAT Thermogenesis}

Despite the many studies exploring the role of p38 pathway in BAT thermogenesis, few of them have assessed the specific roles of the individual p38 family members in BAT activation. In 2005, Robidoux and colleagues (92) reported that p38 $\alpha$ is the main p38 responsible for BAT activation. However, this study was based on in vitro approaches and in vivo experiments with small interfering RNAs (siRNA) and non-specific chemical compounds that inhibit not only $\mathrm{p} 38 \alpha$, but also $\mathrm{p} 38 \beta$. Analysis by our group and others using genetically modified mouse models demonstrated that p38 $\alpha$ deletion results in the upregulation of BAT signature genes in brown adipocytes in a cell-autonomous manner $(10,66)$. We also found that lack of $\mathrm{p} 38 \alpha$ induces $\mathrm{p} 38 \delta$ activation, resulting in increased BAT thermogenesis and energy expenditure. Thus, $\mathrm{p} 38 \delta$, and not $\mathrm{p} 38 \alpha$, seems to be the main $\mathrm{p} 38$ kinase implicated in the induction of BAT thermogenesis in mouse models (Figure 3).

\section{P38 AND WHITE ADIPOSE TISSUE BROWNING}

In addition to the established classification of fat depots as WAT and BAT, a third type of fat cell-called brite, beige, or brownlike adipocytes - has been described in recent years $(19,93)$. Beige adipocytes are characterized by multilocular lipid droplets, high mitochondrial content and metabolic rate, elevated UCP1 expression, and a thermogenic ability similar to BAT. Beige adipocytes arise in WAT depots through a process called browning $(70,94)$, and the induction of WAT browning is a promising therapeutic strategy for increasing total energy expenditure in metabolic disease $(95,96)$, in which the capacity for browning is reduced $(97,98)$. Browning was first described by Young et al. (99) in cold-exposed parametrial fat pads. Since then, the presence of beige adipocytes has been reported in other white fat depots, including epididymal and peri-renal fat (100-102) and especially subcutaneous fat, the fat depot most susceptible to generating brown-like cells in mice (19, 103). In adult humans, most BAT is in fact composed of beige adipocytes $(94,104)$, and a recent report found browning markers to be more highly expressed in visceral than in subcutaneous WAT, opposite to the situation in mice, suggesting that visceral adipose tissue is the brownest depot in humans (105). Since visceral fat is the main fat linked to metabolic diseases (106), these results enhance the importance of WAT browning as a potential therapeutic strategy. Interestingly, WAT browning seems to differ between the sexes and to change with the seasons (107-110).

It is still unclear what specific mechanisms drive browning: differentiation of pre-existing brown adipocyte precursors within WAT, differentiation from white adipocyte precursors, or transdifferentiation from mature white adipocytes (111-114). A non-BAT origin is supported by the fact that BAT arises from Myf5-positive progenitors, whereas the progenitors of beige adipocytes are Myf5-negative (19). In addition to brown signature markers, beige adipocytes also express beige-specific markers, thus defining a beige fat phenotype different from BAT $(94,111,115,116)$.

WAT browning is an adaptive mechanism activated by a range of stress situations. Aside from cold, other stimuli include exercise, hormones, pharmacological activation, and numerous natural compounds $(1,117-121)$. All these stimuli, despite activating browning via distinct internal mediators, converge on the expression of UCP1, mitochondrial biogenesis, and FFA oxidation, similar to the transformation occurring in BAT activation $(74,117)$. p38 signaling has been shown to be an important pathway controlling UCP1 expression in browning (Figure 4).

$\beta 3 \mathrm{AR}$ activation in WAT was thought to be primarily related to lipolysis, activating HSL and inhibiting perilipin to provide FFA during fasting (122). However, recent work has shown that WAT, like BAT, is highly innervated by the SNS and that adrenergic stimulation (by cold, nutrients, or drugs) is also involved in WAT browning in mice $(70,94,123-127)$ and humans (128). The SNS induces the release of cathecolamines like norepinephrine, which, through binding to $\beta 3 \mathrm{AR}$, trigger PKA and p38 activation and promote UCP1 transcription partly via p38-mediated modulation of ATF2 and PGC1 $\alpha$ transcriptional activity (129) (Figure 4). UCP1 expression is also activated via $\beta 3 \mathrm{AR}$-stimulated p38 activation by a series of naturally occurring compounds, such as thymol (130), cinnamaldehyde (131), L-rhamnose (132), grape pomace extract (133), and mangiferin (134). Along with $\beta 3 \mathrm{AR}$ pathway induction, cold-induced WAT browning is also mediated by stimulation of the histamine $\mathrm{H} 4$ receptor, which acts through intracellular calcium mobilization and p38 and ERK activation, promoting PGC1 $\alpha$ and UCP1 expression (135).

Besides, the $\beta 3 \mathrm{AR}-\mathrm{PKA}-\mathrm{p} 38$ pathway, a parallel browning system also converging on $\mathrm{p} 38$ was described by Bordicchia et al. (86). Cardiac NPs, known as controllers of hemodynamic homeostasis (136), are increased by cold stimulation and activate NPRA, which triggers cGMP synthesis and subsequent PKG activation, leading to $\mathrm{p} 38$ phosphorylation and activation of the WAT thermogenic program via $\operatorname{ATF} 2(86,136)$. Mice with high NP signaling in adipose tissue are thus protected against diet-induced obesity and insulin resistance (137), revealing an important heart-adipose connection in the regulation of energy metabolism (136). In this way, catecholamines and NPs are able to act synergistically to promote WAT browning, not only through p38, but also through mTORC1 in an Akt-independent manner $(138,139)$. 


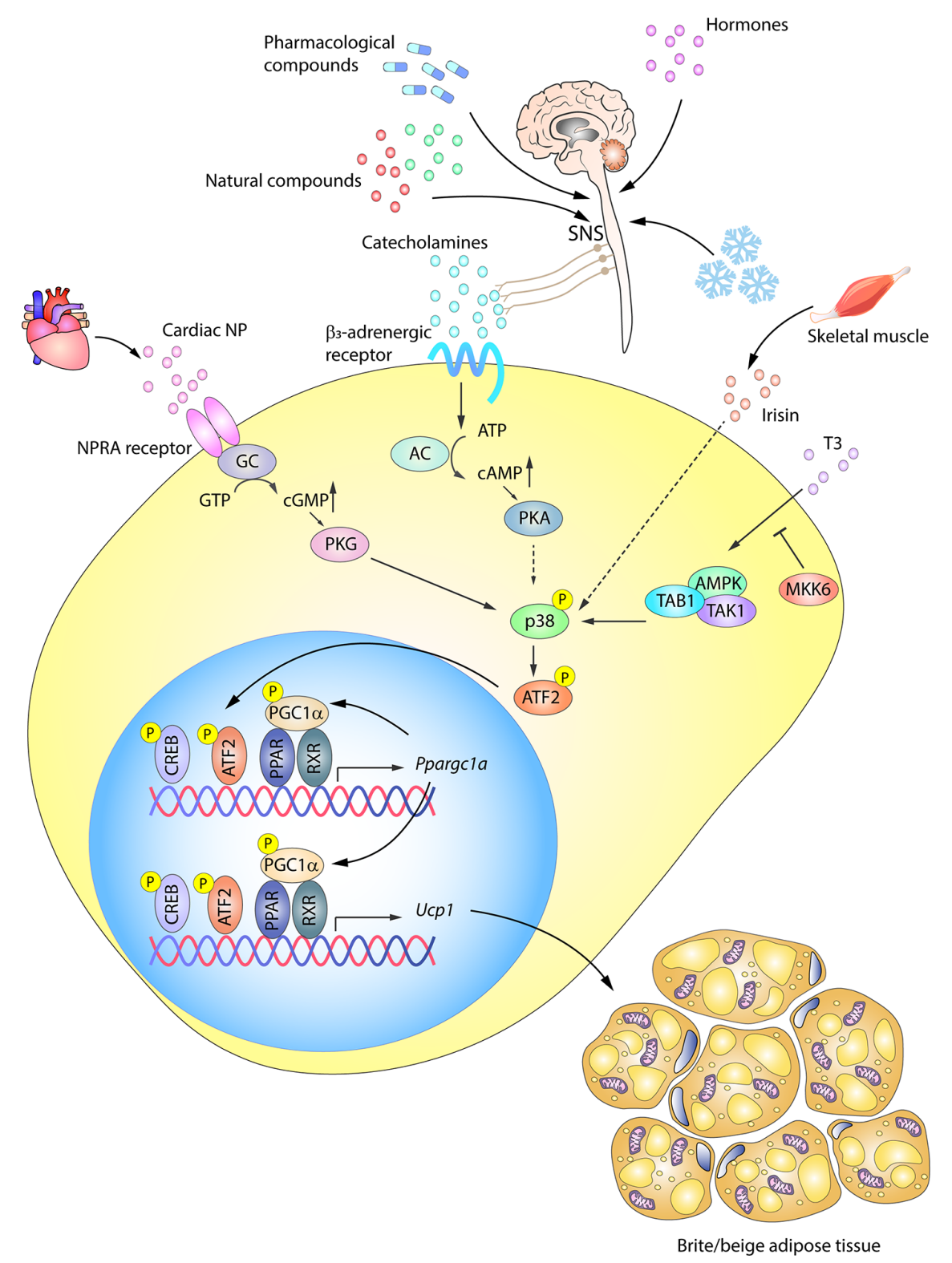

FIGURE 4 | p38-signaling in white adipose tissue browning. WAT browning can be triggered by a variety of stimuli that converge on p38 signaling. In response to cold, hormones, drugs, or naturally occurring compounds, the SNS releases catecholamines to induce WAT browning by stimulating $\beta 3$-adrenergic receptors. The ensuing PKA activation in turn activates p38. p38 phosphorylation and activation can alternatively be triggered by other molecules, such as cardiac NP acting via PKG, T3 hormone via an alternative pathway, or irisin released by skeletal muscle. Solid arrows represent the direct effects of molecular players involved in the indicated signaling pathways, while dotted arrows represent indirect effects, meaning that other unknown molecules might be involved. Active p38 phosphorylates the transcription factor ATF2, which translocates to the nucleus and upregulates the transcription of UCP1 and other key genes essential for transforming white adipocytes into beige adipocytes. AC, adenylate cyclase; AMPK, AMP-activated protein kinase; ATF2, activating transcription factor 2; cAMP, cyclic AMP; GC, guanylate cyclase; cGMP, cyclic GMP; CREB, cAMP response element-binding; MKK6, mitogen-activated protein kinase kinase 6; NP, natriuretic peptides; PGC1 $\alpha$ / Ppargc1a, peroxisome proliferator-activated receptor gamma coactivator $1 \alpha$; PKA, protein kinase A; PKG, protein kinase G; PPAR, peroxisome proliferator-activated receptor; RXR, retinoid X receptor; SNS, sympathetic nervous system; TAB1, TAK1 binding protein 1; TAK1, transforming growth factor beta-activated kinase 1; Ucp1, uncoupling protein 1. Yellow circled 'P' indicates phosphorylation.

WAT browning can also be activated by $\mathrm{TH}$, either indirectly through enhanced adrenergic induction of UCP1 (140-142) or by direct action on white adipocytes $(12,143,144)$. Recent work by our group revealed a new regulation of T3 activity-induced browning in white adipocytes in which $\mathrm{p} 38$ plays a prominent role (12). Mice lacking the p38-upstream activator MKK6 are resistant to obesity and show elevated browning; these effects are reversed by propylthiouracil (PTU)-mediated inhibition of TH production and restored by treatment with exogenous $\mathrm{T} 3$, showing that the phenotype is due to increased T3 sensitivity. 
Furthermore, Mkk6 deletion increases T3-stimulated UCP1 expression in white adipocytes through the activation of p38 via an alternative pathway involving AMPK, TAK, and TAK1 binding protein 1 (TAB1). In obese patients, MKK6 expression is increased and blocks T3-mediated UCP1 induction, preventing WAT browning in the overfed state (12).

WAT browning in mice is also linked to exercise, although human studies have failed to show an effect after endurance training (145). Browning involves several endocrine mediators released from skeletal muscle, the most notable being irisin, despite controversy about its physiological relevance in humans (146-148). Increased irisin levels in exercised mice (12) enhance total body energy expenditure, activate the thermogenic program in vitro, increase lipolysis, and induce a browning phenotype in obesity $(80,149,150)$. Irisin-stimulated browning in mice was reported to require p38 signaling $(80,151)$ (Figure 4). In addition, carnosine, a dipeptide abundant in muscle, brain and other tissues, might induce browning and thermogenesis in obese rats through the stimulation of irisin, which up-regulates UCP1, PGC1 $\alpha$, and CD137 via p38 in inguinal WAT (152).

WAT browning is also promoted by BMPs. BMP7 induces UCP1 in mouse subcutaneous WAT and in human adipocytes (153, 154), hinting that the BMP7-p38 signaling mechanism operating during BAT adipogenesis might also operate in WAT (17). BMP4 is expressed in human subcutaneous and visceral fat, and its expression correlates inversely with BMI (155), suggesting that hypertrophic obesity is a condition of pre-adipocyte resistance to BMP4 (156). BMP4 stimulates browning in mouse and human white pre-adipocytes, and its overexpression in mice increases inguinal WAT browning $(153,155,157)$. This induction was reported to be mediated by $\mathrm{p} 38-\mathrm{ATF} 2$ signaling and activation of PGC1 $\alpha$ (155). Growth differentiation factor 5 (GDF5), another TGF- $\beta$ superfamily member, promotes thermogenic gene expression and subcutaneous WAT browning in mice, in part through p38 activation (158).

A number of other molecules have been reported to induce browning in a p38-dependent manner. Fibroblast growth factor 21 (FGF21) is induced in BAT by cold, in liver by nutrients and hormones, and in muscle by exercise (121) and acts as an inducer of WAT browning (159-162). FGF21 contributes to browning in three ways: by regulating the SNS through its action in the brain, by enhancing adrenergic stimulation of UCP1 (163), or by acting directly on white adipocytes to activate PGC1 $\alpha$ (164). Another browning factor is the lipid sensor GPR120, which promotes browning in mice and adipocytes through p38-mediated FGF21 release (165). UCP1 and PGC1 $\alpha$ are also induced by retinoic acid treatment in mice (166), apparently through p38 (167). The gutrestricted FXR agonist fexaramine (Fex) protects against dietinduced weight gain by promoting thermogenesis through the expression of UCP1 and PGC1 $\alpha$ in WAT, also possibly via 338 (168). Browning is also promoted by the autocrine glycoprotein follistatin, which acts via p38 to increase the expression of beige adipocyte-specific markers and genes involved in thermogenesis, FA oxidation, and mitochondrial biogenesis in epididymal WAT and subcutaneous WAT (102). WAT browning in mice is stimulated by overexpression of zinc alpha 2 glycoprotein
(ZAG) (169), and in 3T3-L1 white adipocytes ZAG increases the expression of brown fat markers and induces mitochondrial biogenesis via PKA and p38 signaling (170). The naturally occurring compound cryptotanshinone promotes brown-tissue and beige-cell markers by activating AMPK, p38, and Smad1/5 (58), whereas sinapic acid achieves the same effect via AMPK, p38, and PGC1 $\alpha$ (171). Treatment with the non-steroidal antiinflammatory drug ketoprofen induces browning in 3T3-L1 cells and inguinal WAT, increasing mitochondrial biogenesis through an intricate signaling pathway involving $\mathrm{p} 38$, mTORC1, and COX activation (172).

Until now, p38 $\alpha$ was considered the family member implicated in browning, inducing UCP1 expression $(13,92)$. This assumption based largely on data from cell culture studies using $\mathrm{p} 38 \alpha$ inhibitors, which blunt stimulation of the thermogenic program. However, non-specific effects of these inhibitors cannot be excluded, and several studies have shown that these inhibitors reduce p38 phosphorylation, revealing inhibition of upstream kinases, which in some cases might result in hyperactivation of other p38 isoforms (86, 102, 130, $132,133,151,170)$. Despite these concerns about inhibitor specificity, studies with $\mathrm{p} 38 \alpha$ genetic mutant mice were not reported until recently. Two parallel studies, one from our group, recently showed that ablation of $\mathrm{p} 38 \alpha$ in mouse adipose tissue surprisingly activates the thermogenic program $(10,66)$. Mice with adipocyte $\mathrm{p} 38 \alpha$ deficiency are lean, have improved metabolism, and are resistant to diet-induced obesity due to increased BAT thermogenesis and browning in inguinal WAT associated with enhanced CREB transcription activity $(10,66)$. However, we showed that in epididymal adipose tissue adipocyte p38 $\alpha$ deficiency results in reduced browning (12). These studies show that the mechanisms controlling the thermogenic program, thought to be similar in brown and beige adipocytes, may differ between each fat depot. Distinct p38 family members may be implicated in these processes; thus, while p38 $\alpha$ would block thermogenesis in BAT by inhibiting $\mathrm{p} 38 \delta$, in inguinal WAT it might abolish UCP1 expression by inhibiting $\mathrm{p} 38 \gamma$, and in epidydimal WAT it could induce browning $(10,12)$.

\section{ROLE OF P38 IN ADIPOSE TISSUE SECRETION}

Adipose tissue is not only an energy reservoir, but also a secretory organ. The endocrine function of adipose tissue was discovered in the 1994 with the description of leptin (173). Since then, research has identified several other bioactive molecules secreted by adipocytes, called adipokines. Adipokines are released to the circulation and modulate metabolic processes in the body through actions on metabolic organs such as the liver and brain $(174,175)$. Adipokines are implicated in metabolic disorders such as obesity and are important targets in the treatment of obesity-related diseases. Adipokines with wellknown regulatory functions include leptin, adiponectin, tumor necrosis factor $\alpha$ (TNF $\alpha$ ), and interleukin-6 (IL6) (173, 176, 177). Adipokine secretion was initially thought to be limited to 
WAT, but lately it has become clear that BAT is also a source of adipokines with specific functions and produced in a distinct repertoire from that of WAT $(74,178)$.

The secretion of many of these adipokines likely involves SAPKs, which trigger the inflammatory response in many cells and control the secretion of pro-inflammatory mediators such as TNF $\alpha$ or IL6 $(177,179)$. Activation of adipocyte JNK1 is partially responsible for the increased levels of IL6 in obesity (8), and palmitate- or insulin resistance-stimulated JNK is also critical for adipocyte production of the chemokine MCP1. Chemical inhibition of JNK activity suppresses MCP1 release $(180,181)$. JNK also mediates the secretion of adipokines with noninflammatory properties. Our group recently demonstrated that adipocyte JNK1 controls adiponectin levels in mice (182). Testosterone activates JNK in adipose tissue, and ablation of adipose JNK1 results in increased serum adiponectin, whereas activation of JNK in male adipose tissue correlates with reduced adiponectin levels (182).

There are promising data suggesting that p38 might regulate the adipose tissue secretome. In 2002, Finck and Johnson showed that chemical inhibition of p38 almost completely blocks TNF $\alpha$ induced leptin expression in mice (183). Interestingly however, $\mathrm{TNF} \alpha$ might have an opposite role in the regulation of leptin secretion. In the absence of corticosteroid medication with dexamethasone, TNF $\alpha$ inhibits leptin secretion, but in the presence of glucocorticoid treatment TNF $\alpha$ has the opposite effect. In cultured omental adipose tissue from dexamethasonetreated patients, the synergistic effect of TNF $\alpha$ on leptin secretion is blocked by $\mathrm{p} 38$ chemical inhibition, indicating that the effect of p38 on leptin secretion might be mediated by glucocorticoid receptor activation (184). More recently, Uchiyama et al. found, using a p38 chemical inhibitor in cultured adipocytes, that alamandindecreased leptin expression was also mediated by p38 (185). Moreover, leptin expression is increased in in vitro differentiated p38 $\alpha$-deficient adipocytes (10). These studies thus suggest that p38 could be involved in leptin secretion by WAT; however, given the lack of specificity of the inhibitors used in these studies and their potential p38-independent effects, additional studies with genetic mouse models will be needed to fully define the role of p38 in the regulation of leptin secretion. p38 has also been suggested to regulate the secretion of adiponectin in obese human adipose tissue (186).

There are also recent studies implicating the $\mathrm{p} 38$ pathway in the secretion of adipokines by brown adipocytes (187). The metabolic regulator FGF21 is secreted by BAT after thermogenic stimulation. Brown adipocyte expression of FGF21 requires p38 activation, and p $38 \alpha / \beta$ inhibition impairs FGF21 transcriptional induction upon exposure to norepinephrine, the free-fatty acid receptor selective agonist GW9508, or eicosapentanoic acid (14, 165). Moreover, transfection of a brown adipocyte cell line with a constitutively active form of the p38 upstream kinase MKK6 increases FGF21 expression, while a dominant-negative form abolishes its induction by cAMP and PKA (14). Also during BAT thermogenesis, the cAMP-dependent chemokine CXCL14 recruits and polarizes macrophages to the M2 phenotype (188), and induction of Cxcl14 mRNA in brown adipocytes is blunted by chemical inhibition of $\mathrm{p} 38 \alpha / \beta$ (188). Nevertheless, further experiments are needed in mice lacking $\mathrm{p} 38 \alpha / \beta$ or their upstream kinases to confirm the role of p38 signaling in CXCL14 secretion (Figure 5).

\section{Role of p38 in Adipose Tissue Inflammation}

The p38 pathway was originally described as a master regulator of pro-inflammatory cytokine secretion in myeloid cells. In macrophages, different p38 family members are involved in the production of pro-inflammatory mediators $(188,189)$ and promote monocytes recruitment exacerbating the adipocyte pro-inflammatory response (189). Adipocytes are a major source of TNF $\alpha$ and IL6, and p38 inhibition partially blocks adipocyte TNF $\alpha$-induced IL6 secretion, suggesting that the regulatory actions of $\mathrm{p} 38 \mathrm{~s}$ observed in macrophages might also operate in adipose tissue (184). Moreover, siRNA or chemical p38 inhibition impairs IL6 secretion by amlexanox-treated 3T3L1 adipocytes, and this inhibitory effect is also observed in WAT from mice treated with p38 inhibitors (190). In this study, inhibition of IKK $\varepsilon / \mathrm{TBK} 1$ by amlexanox led to an increase in cAMP levels that triggered p38 activation in adipocytes and subcutaneous WAT (190). This is interesting because the cAMPp38 pathway is crucial for the thermogenic process in BAT (13). Given that IKKE/TBK1 inhibition does not increase IL6 expression in BAT, this mechanism might be specific to subcutaneous WAT depots, which are enriched in browningsusceptible beige adipocytes. IL6 has been shown to be required for the induction of browning in subcutaneous depots after cold exposure (191).

TNF $\alpha$ is chronically elevated in adipose tissue from obese mice and humans and is a main activator of the p38 pathway in several cell types (5). These abnormal levels of TNF $\alpha$ lead to the activation of stress signaling cascades that stimulate lipolysis in adipocytes impairing lipid handling capacity (192). The involvement of JNK in TNF- $\alpha$ stimulation of lipolysis in human adipocytes have been demonstrated (193), however a possible role of p38 family members in TNF-induced lipolysis need to be clarified. TNF $\alpha$ has been proposed to induce plasminogen activator inhibitor-1 (PAI-1) in adipocytes, an adipokine that contributes to the cardiovascular and metabolic complications associated with obesity (194). p38 inhibition impairs TNF $\alpha$-induced PAI-1 expression in 3T3-L1 adipocytes, suggesting that this PAI-1 expression is p38 dependent (195). Similar results were found in a later study, in which $\mathrm{p} 38$ chemical inhibition partially decreased PAI-1 expression induced by $\beta 3 \mathrm{AR}$ activation in 3T3-L1 adipocytes (196). Nevertheless, chemical inhibition of p38 did not have the same effect in epididymal WAT from mice treated with a $\beta 3 \mathrm{AR}$ agonist (196). p38 inhibition also blocks TNF $\alpha$ induction of Wdnm1-like adipokine in 3T3-L1 adipocytes (197). These data are consistent with p38 mediation of TNF $\alpha$-regulated adipokine expression (Figure 5). However, additional studies with animal models will be needed to confirm the role of p38 in the secretion of these adipokines.

Pro-inflammatory signals are important players of the BAT and beige adipocytes thermogenesis. Many inflammatory cells and proinflammatory cytokines secreted by both immune cells and 

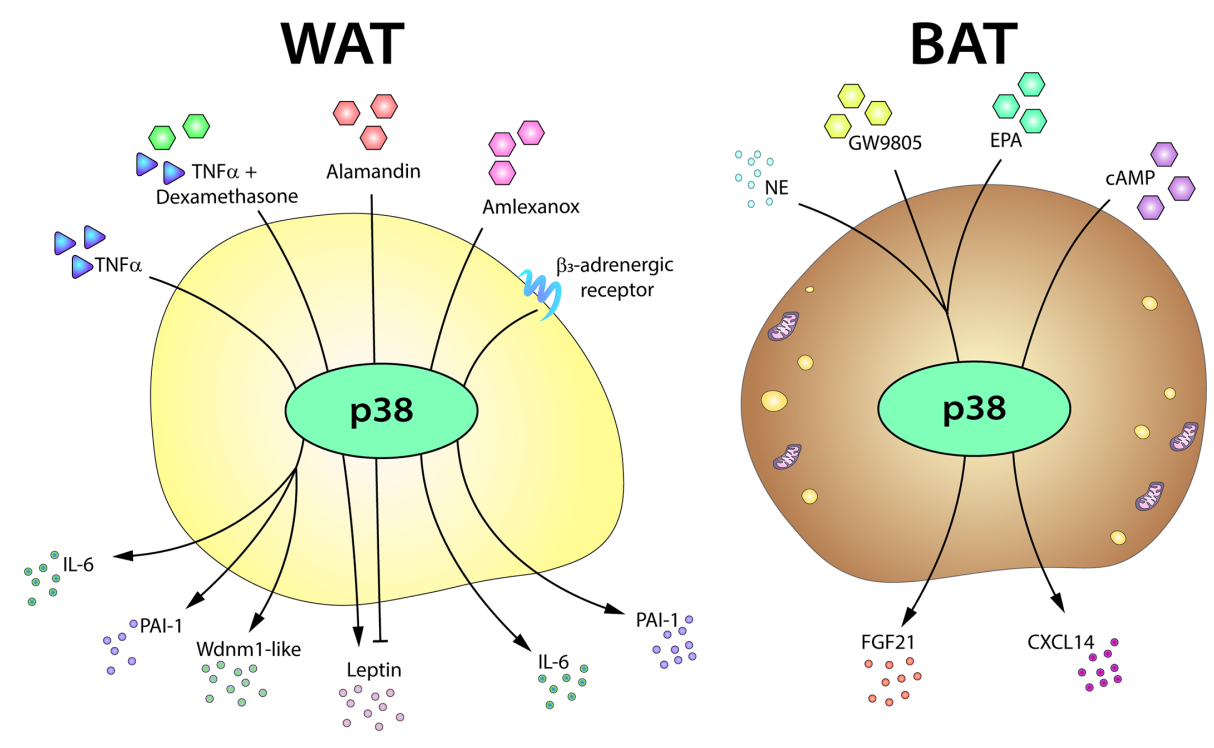

FIGURE 5 | The p38-mediated adipose tissue secretome. The p38 pathway controls the expression or secretion of distinct adipokines in WAT and BAT. In white adipocytes, p38 activation is required for the production of IL6, PAI-1, and Wdnm1-like after TNF $\alpha$ stimulation. p38 signaling also controls leptin secretion in response to TNF $\alpha$, playing a positive role in the presence of dexamethasone, but an inhibitory role in response to alamandin. p38 is also involved in the secretion of IL6 in response to amlexanox and in the induction of PAl-1 after $\beta 3 A R$ stimulation. In brown adipocytes, p38 controls the secretion of FGF21 induced by NE, GW9805, or EPA and directs the secretion of CXCL14 after CAMP stimulation. CAMP, cyclic AMP; EPA, eicosapentanoic acid; FGF21, fibroblast growth factor 21; IL6, interleukin-6; NE, norepinephrine; PAl-1, plasminogen activator inhibitor-1; TNF $\alpha$, tumor necrosis factor $\alpha$.

adipocytes can negatively affect the thermogenic activation and browning of WAT (198). As it has been commented above, p38 controls the expression of many pro-inflammatory cytokines by macrophages (199) and also controls the secretion of the M2 chemokine CXCL14 (188). In addition, upon cold exposure, mice lacking adipose $\mathrm{p} 38 \alpha$ have an increased mRNA expression of M2-related genes, a reduction in mRNA levels of proinflammatory cytokines, and an elevated macrophage infiltration in inguinal WAT (66). These results are in agreement with the increased browning in this mouse model, given that proinflammatory M1 macrophages infiltration in BAT impairs its ability to respond to thermogenic stimuli (200-202), while M2 macrophages are proposed to be directly involved in promoting BAT thermogenesis (203).

\section{FUTURE PERSPECTIVES}

Adipose tissue is an important organ in metabolic regulation. Much more than a simple fuel reservoir, adipose tissue has endocrine functions and is able to massively expand or retract according to the nutrient supply. This unique, almost unlimited capacity of adipose tissue is critical for maintaining homeostasis, and its disturbance is directly linked to obesity and related disorders and comorbidities. Increasing knowledge about adipose tissue biology has led to a better understanding of its role in health and disease. p38 stress kinases are one of a major regulators of cell adaptation to external and internal changes and play important roles in adipose tissue. In recent years, significant advances have defined the roles of p38 kinases in different adipocyte cell types. However, the use of pharmacological inhibitors in most studies and the limited data from genetically modified animals show the need for caution in interpreting these findings while further research is undertaken. The use of chemical inhibitors has important limitations because of their nonspecificity and side effects. Additionally, inhibitors with selective activity against $\mathrm{p} 38 \alpha$ and $\mathrm{p} 38 \beta$ might affect $\mathrm{p} 38 \gamma$ and $\mathrm{p} 38 \delta$ activation due to the negative feedback exerted by $\mathrm{p} 38 \alpha$ on the upstream activators of the pathway, MKK3/MKK6. Other hurdles to progress are the lack of antibodies recognizing the phosphorylated form of each family member and the small number of substrates identified for the less studied family members. Research in the coming years, using appropriate genetically modified animal models and evaluating the phosphorylation of specific substrates of each family member, is expected to better define the role of the all p38s in adipose tissue. For example, research in adipogenesis would need to assess the role of each p38 in the differentiation of adipose tissue in steadystate and in obesity. More importantly, research is needed to identify the main p38 family member involved in human adipose tissue browning and BAT activation in order to define the potential of this pathway as a target for obesity treatment.

BAT activation and browning have emerged as therapeutic targets for the treatment of obesity and its associated diseases. We recently demonstrated that inhibition of $\mathrm{p} 38 \alpha$ leads to the hyperactivation of $\mathrm{p} 38 \delta$ and that active $\mathrm{p} 38 \delta$ increases thermogenesis. This finding has important clinical implications because $\mathrm{p} 38 \alpha$ inhibition or $\mathrm{p} 38 \delta$ activation might be feasible therapeutic approaches to the treatment of obesity-related disorders. What is required now is the design of selective 
inhibitors or activators targeting the appropriate p38 family member. These specific molecules might allow prevent the progression of obesity and treat clinical obese patients.

Another important goal is the identification of p38dependent cytokines, adipokines or batokines susceptible to modulation by manipulation of the p38 pathway. The existing evidence of an association between some adipokines and batokines and the p38 pathway will need to be confirmed using appropriate genetic tools.

From the evidence explored in this review, it is clear that targeting the p38 pathway in adipose tissue can provide a firm and timely understanding of obesity and its associated pathologies in the era of the global obesity pandemic.

\section{AUTHOR CONTRIBUTIONS}

Each author contributed to the literature search and wrote a section of the manuscript. IN drew the figures, which were revised by all authors. All authors contributed to the article and approved the submitted version.

\section{FUNDING}

ML was supported by a Spanish grant MINECO-FEDERSAF2015-74112-JIN and Fundación AECC: INVES20026LEIV.

\section{REFERENCES}

1. Aldiss P, Betts J, Sale C, Pope M, Budge H, Symonds ME. Exercise-induced ‘browning' of adipose tissues. Metab Clin Exp (2018) 81:63-70. doi: 10.1016/ j.metabol.2017.11.009

2. Algire C, Medrikova D, Herzig S. White and brown adipose stem cells: from signaling to clinical implications. Biochim Biophys Acta (2013) 1831(5):896904. doi: 10.1016/j.bbalip.2012.10.001

3. Valencak TG, Osterrieder A, Schulz TJ. Sex matters: The effects of biological sex on adipose tissue biology and energy metabolism. Redox Biol (2017) 12:806-13. doi: 10.1016/j.redox.2017.04.012

4. Stern JH, Rutkowski JM, Scherer PE. Adiponectin, Leptin, and Fatty Acids in the Maintenance of Metabolic Homeostasis through Adipose Tissue Crosstalk. Cell Metab (2016) 23(5):770-84. doi: 10.1016/j.cmet.2016.04.011

5. Sabio G, Davis RJ. TNF and MAP kinase signalling pathways. Semin Immunol (2014) 26(3):237-45. doi: 10.1016/j.smim.2014.02.009

6. Manieri E, Sabio G. Stress kinases in the modulation of metabolism and energy balance. J Mol Endocrinol (2015) 55(2):R11-22. doi: 10.1530/JME-15-0146

7. Hirosumi J, Tuncman G, Chang L, Gorgun CZ, Uysal KT, Maeda K, et al. A central role for JNK in obesity and insulin resistance. Nature (2002) 420:333-6. doi: 10.1038/nature01137

8. Sabio G, Das M, Mora A, Zhang Z, Jun JY, Ko HJ, et al. A stress signaling pathway in adipose tissue regulates hepatic insulin resistance. Science (2008) 322:1539-43. doi: 10.1126/science.1160794

9. Aouadi M, Laurent K, Prot M, Le Marchand-Brustel Y, Binetruy B, Bost F. Inhibition of p38MAPK increases adipogenesis from embryonic to adult stages. Diabetes (2006) 55(2):281-9. doi: 10.2337/diabetes.55.02.06.db05-0963

10. Matesanz N, Nikolic I, Leiva M, Pulgarin-Alfaro M, Santamans AM, Bernardo E, et al. p38alpha blocks brown adipose tissue thermogenesis through p38delta inhibition. PloS Biol (2018) 16(7):e2004455. doi: 10.1371/ journal.pbio. 2004455

11. Haim Y, Bluher M, Konrad D, Goldstein N, Kloting N, Harman-Boehm I, et al. ASK1 (MAP3K5) is transcriptionally upregulated by E2F1 in adipose tissue in
MP was a fellow of the Spanish State programme for the Promotion of Talent and its Employment (PRE2018-083631). IN was funded by the EFSD/Lilly grants (2017 and 2019), the CNIC IPP FP7 Marie Curie Programme (PCOFUND-2012600396), an EFSD Rising Star award (2019), and the JDC2018-Incorporación (MIN/JDC1802). GS received funding from the following programs and organizations: European Union Seventh Framework Programme (FP7/2007-2013) under grant agreement $n^{\circ}$ ERC 260464, the EFSD/Lilly European Diabetes Research Programme, the BBVA Foundation Leonardo Grants program for Researchers and Cultural Creators (Investigadores-BBVA-2017) IN[17]_BBM_BAS_0066, MINECO-FEDER SAF2016-79126-R, and the Comunidad de Madrid (IMMUNOTHERCAN-CM S2010/BMD-2326 and B2017/BMD-3733). The CNIC is supported by the Instituto de Salud Carlos III (ISCIII), the Ministerio de Ciencia, Innovación y Universidades (MCNU), and the Pro CNIC Foundation and is a Severo Ochoa Center of Excellence (SEV-2015-0505).

\section{ACKNOWLEDGMENTS}

We thank our collaborators and the students and fellows who contributed to the studies in the Sabio group over the years. We regret the inadvertent omission of important references due to space limitations. S Bartlett (CNIC) provided English editing.

obesity, molecularly defining a human dys-metabolic obese phenotype. $\mathrm{Mol}$ Metab (2017) 6(7):725-36. doi: 10.1016/j.molmet.2017.05.003

12. Matesanz N, Bernardo E, Acin-Perez R, Manieri E, Perez-Sieira S, HernandezCosido L, et al. MKK6 controls T3-mediated browning of white adipose tissue. Nat Commun (2017) 8(1):856. doi: 10.1038/s41467-017-00948-Z

13. Cao W, Daniel KW, Robidoux J, Puigserver P, Medvedev AV, Bai X, et al. p38 mitogen-activated protein kinase is the central regulator of cyclic AMPdependent transcription of the brown fat uncoupling protein 1 gene. $\mathrm{Mol}$ Cell Biol (2004) 24(7):3057-67. doi: 10.1128/mcb.24.7.3057-3067.2004

14. Hondares E, Iglesias R, Giralt A, Gonzalez FJ, Giralt M, Mampel T, et al. Thermogenic activation induces FGF21 expression and release in brown adipose tissue. J Biol Chem (2011) 286(15):12983-90. doi: 10.1074/ jbc.M110.215889

15. Cao W, Medvedev AV, Daniel KW, Collins S. beta-Adrenergic activation of p38 MAP kinase in adipocytes: cAMP induction of the uncoupling protein 1 (UCP1) gene requires p38 MAP kinase. J Biol Chem (2001) 276(29):2707782. doi: 10.1074/jbc.M101049200

16. Teruel T, Hernandez R, Benito M, Lorenzo M. Rosiglitazone and retinoic acid induce uncoupling protein-1 (UCP-1) in a p38 mitogen-activated protein kinase-dependent manner in fetal primary brown adipocytes. J Biol Chem (2003) 278(1):263-9. doi: 10.1074/jbc.M207200200

17. Tseng YH, Kokkotou E, Schulz TJ, Huang TL, Winnay JN, Taniguchi CM, et al. New role of bone morphogenetic protein 7 in brown adipogenesis and energy expenditure. Nature (2008) 454:1000-4. doi: 10.1038/ nature 07221

18. Whittle AJ, Carobbio S, Martins L, Slawik M, Hondares E, Vazquez MJ, et al. BMP8B increases brown adipose tissue thermogenesis through both central and peripheral actions. Cell (2012) 149(4):871-85. doi: 10.1016/ j.cell.2012.02.066

19. Harms M, Seale P. Brown and beige fat: development, function and therapeutic potential. Nat Med (2013) 19(10):1252-63. doi: 10.1038/nm.3361

20. Villarroya F, Vidal-Puig A. Beyond the sympathetic tone: the new brown fat activators. Cell Metab (2013) 17(5):638-43. doi: 10.1016/j.cmet.2013.02.020 
21. Sellayah D, Bharaj P, Sikder D. Orexin is required for brown adipose tissue development, differentiation, and function. Cell Metab (2011) 14(4):478-90. doi: 10.1016/j.cmet.2011.08.010

22. Kajimura S, Seale P, Tomaru T, Erdjument-Bromage H, Cooper MP, Ruas JL, et al. Regulation of the brown and white fat gene programs through a PRDM16/CtBP transcriptional complex. Genes Dev (2008) 22(10):1397-409. doi: $10.1101 / \mathrm{gad} .1666108$

23. Schulz TJ, Tseng YH. Brown adipose tissue: development, metabolism and beyond. Biochem J (2013) 453(2):167-78. doi: 10.1042/bj20130457

24. Giralt M, Villarroya F. White, brown, beige/brite: different adipose cells for different functions? Endocrinology (2013) 154(9):2992-3000. doi: 10.1210/ en.2013-1403

25. Sanchez-Gurmaches J, Guertin DA. Adipocyte lineages: tracing back the origins of fat. Biochim Biophys Acta (2014) 1842(3):340-51. doi: 10.1016/ j.bbadis.2013.05.027

26. Park A, Kim WK, Bae KH. Distinction of white, beige and brown adipocytes derived from mesenchymal stem cells. World J Stem Cells (2014) 6(1):33-42. doi: $10.4252 /$ wjsc.v6.i1.33

27. Sarjeant K, Stephens JM. Adipogenesis. Cold Spring Harbor Perspect Biol (2012) 4(9):a008417. doi: 10.1101/cshperspect.a008417

28. Rosen ED, MacDougald OA. Adipocyte differentiation from the inside out. Nat Rev Mol Cell Biol (2006) 7(12):885-96. doi: 10.1038/nrm2066

29. Tang QQ, Lane MD. Adipogenesis: from stem cell to adipocyte. Annu Rev Biochem (2012) 81:715-36. doi: 10.1146/annurev-biochem-052110-115718

30. Suenaga M, Kurosawa N, Asano H, Kanamori Y, Umemoto T, Yoshida H, et al. Bmp4 expressed in preadipocytes is required for the onset of adipocyte differentiation. Cytokine (2013) 64(1):138-45. doi: 10.1016/j.cyto.2013.07.011

31. Park JH, Lee SB. An essential role for Ewing sarcoma gene (EWS) in early white adipogenesis. Obesity (Silver Spring Md) (2015) 23(1):138-44. doi: 10.1002/oby.20934

32. Modica S, Straub LG, Balaz M, Sun W, Varga L, Stefanicka P, et al. Bmp4 Promotes a Brown to White-like Adipocyte Shift. Cell Rep (2016) 16 (8):2243-58. doi: 10.1016/j.celrep.2016.07.048

33. Seale P, Bjork B, Yang W, Kajimura S, Chin S, Kuang S, et al. PRDM16 controls a brown fat/skeletal muscle switch. Nature (2008) 454:961-7. doi: 10.1038/nature07182

34. Engelman JA, Lisanti MP, Scherer PE. Specific inhibitors of p38 mitogenactivated protein kinase block 3T3-L1 adipogenesis. J Biol Chem (1998) 273 (48):32111-20. doi: 10.1074/jbc.273.48.32111

35. Aouadi M, Jager J, Laurent K, Gonzalez T, Cormont M, Binetruy B, et al. p38MAP Kinase activity is required for human primary adipocyte differentiation. FEBS Lett (2007) 581(29):5591-6. doi: 10.1016/j.febslet. 2007.10.064

36. Engelman JA, Berg AH, Lewis RY, Lin A, Lisanti MP, Scherer PE. Constitutively active mitogen-activated protein kinase kinase 6 (MKK6) or salicylate induces spontaneous 3T3-L1 adipogenesis. J Biol Chem (1999) 274 (50):35630-8. doi: 10.1074/jbc.274.50.35630

37. Yang TT, Xiong Q, Enslen H, Davis RJ, Chow CW. Phosphorylation of NFATc4 by p38 mitogen-activated protein kinases. Mol Cell Biol (2002) 22 (11):3892-904. doi: $10.1128 / \mathrm{mcb} .22 .11 .3892-3904.2002$

38. Wang XZ, Ron D. Stress-induced phosphorylation and activation of the transcription factor CHOP (GADD153) by p38 MAP Kinase. Science (1996) 272:1347-9. doi: 10.1126/science.272.5266.1347

39. Bost F, Aouadi M, Caron L, Binetruy B. The role of MAPKs in adipocyte differentiation and obesity. Biochimie (2005) 87(1):51-6. doi: 10.1016/ j.biochi.2004.10.018

40. Rabiee A, Schwammle V, Sidoli S, Dai J, Rogowska-Wrzesinska A, Mandrup $\mathrm{S}$, et al. Nuclear phosphoproteome analysis of 3T3-L1 preadipocyte differentiation reveals system-wide phosphorylation of transcriptional regulators. Proteomics (2017) 17(6):1-15. doi: 10.1002/pmic.201600248

41. Tomas-Loba A, Manieri E, Gonzalez-Teran B, Mora A, Leiva-Vega L, Santamans AM, et al. p38gamma is essential for cell cycle progression and liver tumorigenesis. Nature (2019) 568:557-60. doi: 10.1038/s41586-019$1112-8$

42. Bowers RR, Lane MD. A role for bone morphogenetic protein- 4 in adipocyte development. Cell Cycle (2007) 6(4):385-9. doi: 10.4161/cc.6.4.3804

43. Huang H, Song TJ, Li X, Hu L, He Q, Liu M, et al. BMP signaling pathway is required for commitment of $\mathrm{C} 3 \mathrm{H} 10 \mathrm{~T} 1 / 2$ pluripotent stem cells to the adipocyte lineage. Proc Natl Acad Sci USA (2009) 106(31):12670-5. doi: $10.1073 /$ pnas. 0906266106

44. Heldin $\mathrm{CH}$, Miyazono K, ten Dijke P. TGF-beta signalling from cell membrane to nucleus through SMAD proteins. Nature (1997) 390:465-71. doi: $10.1038 / 37284$

45. Hata K, Nishimura R, Ikeda F, Yamashita K, Matsubara T, Nokubi T, et al. Differential roles of Smad1 and p38 kinase in regulation of peroxisome proliferator-activating receptor gamma during bone morphogenetic protein 2-induced adipogenesis. Mol Biol Cell (2003) 14(2):545-55. doi: 10.1091/ mbc.e02-06-0356

46. Maekawa T, Jin W, Ishii S. The role of ATF-2 family transcription factors in adipocyte differentiation: antiobesity effects of p38 inhibitors. Mol Cell Biol (2010) 30(3):613-25. doi: 10.1128/MCB.00685-09

47. Lee JS, Ha L, Kwon IK, Lim JY. The role of focal adhesion kinase in BMP4 induction of mesenchymal stem cell adipogenesis. Biochem Biophys Res Commun (2013) 435(4):696-701. doi: 10.1016/j.bbrc.2013.05.045

48. Younce CW, Azfer A, Kolattukudy PE. MCP-1 (monocyte chemotactic protein-1)-induced protein, a recently identified zinc finger protein, induces adipogenesis in 3T3-L1 pre-adipocytes without peroxisome proliferatoractivated receptor gamma. J Biol Chem (2009) 284(40):27620-8. doi: 10.1074/jbc.M109.025320

49. Younce C, Kolattukudy P. MCP-1 induced protein promotes adipogenesis via oxidative stress, endoplasmic reticulum stress and autophagy. Cell Physiol Biochem (2012) 30(2):307-20. doi: 10.1159/000339066

50. Tang QQ, Otto TC, Lane MD. Commitment of C3H10T1/2 pluripotent stem cells to the adipocyte lineage. Proc Natl Acad Sci USA (2004) 101(26):960711. doi: 10.1073/pnas.0403100101

51. Wang EA, Israel DI, Kelly S, Luxenberg DP. Bone morphogenetic protein-2 causes commitment and differentiation in C3H10T1/2 and 3T3 cells. Growth Factors (1993) 9(1):57-71. doi: 10.3109/08977199308991582

52. Brunmeir R, Wu J, Peng X, Kim SY, Julien SG, Zhang Q, et al. Comparative Transcriptomic and Epigenomic Analyses Reveal New Regulators of Murine Brown Adipogenesis. PloS Genet (2016) 12(12):e1006474. doi: 10.1371/ journal.pgen.1006474

53. Ning X, He J, Shi X, Yu T, Yang G. Wnt3a regulates mitochondrial biogenesis through p38/CREB pathway. Biochem Biophys Res Commun (2019) 516(3):1019-25. doi: 10.1016/j.bbrc.2016.05.004

54. Caverzasio J, Manen D. Essential role of Wnt3a-mediated activation of mitogen-activated protein kinase p38 for the stimulation of alkaline phosphatase activity and matrix mineralization in C3H10T1/2 mesenchymal cells. Endocrinology (2007) 148(11):5323-30. doi: 10.1210/ en.2007-0520

55. An JH, Yang JY, Ahn BY, Cho SW, Jung JY, Cho HY, et al. Enhanced mitochondrial biogenesis contributes to Wnt induced osteoblastic differentiation of C3H10T1/2 cells. Bone (2010) 47(1):140-50. doi: 10.1016/j.bone.2010.04.593

56. Takeno A, Kanazawa I, Notsu M, Tanaka KI, Sugimoto T. Phloretin Promotes Adipogenesis via Mitogen-Activated Protein Kinase Pathways in Mouse Marrow Stromal ST2 Cells. Int J Mol Sci (2018) 19(6):1-17. doi: 10.3390/ijms19061772

57. Lee HW, Rhee DK, Kim BO, Pyo S. Inhibitory effect of sinigrin on adipocyte differentiation in 3T3-L1 cells: Involvement of AMPK and MAPK pathways. Biomed Pharmacother (2018) 102:670-80. doi: 10.1016/j.biopha.2018.03.124

58. Imran KM, Rahman N, Yoon D, Jeon M, Lee BT, Kim YS. Cryptotanshinone promotes commitment to the brown adipocyte lineage and mitochondrial biogenesis in C3H10T1/2 mesenchymal stem cells via AMPK and p38MAPK signaling. Biochim Biophys Acta Mol Cell Biol Lipids (2017) 1862 (10):1110-20. doi: 10.1016/j.bbalip.2017.08.001

59. Yeow K, Phillips B, Dani C, Cabane C, Amri EZ, Derijard B. Inhibition of myogenesis enables adipogenic trans-differentiation in the $\mathrm{C} 2 \mathrm{C} 12$ myogenic cell line. FEBS Lett (2001) 506(2):157-62. doi: 10.1016/s0014-5793(01) 02900-3

60. Asakura A, Komaki M, Rudnicki M. Muscle satellite cells are multipotential stem cells that exhibit myogenic, osteogenic, and adipogenic differentiation. Differentiation Res Biol Diversity (2001) 68(4-5):245-53. doi: 10.1046/j.14320436.2001.680412.x

61. Sakuma T, Matsumoto T, Kano K, Fukuda N, Obinata D, Yamaguchi K, et al. Mature, adipocyte derived, dedifferentiated fat cells can differentiate 
into smooth muscle-like cells and contribute to bladder tissue regeneration. J Urol (2009) 182(1):355-65. doi: 10.1016/j.juro.2009.02.103

62. Qi R, Liu H, Wang Q, Wang J, Yang F, Long D, et al. Expressions and Regulatory Effects of P38/ERK/JNK Mapks in the Adipogenic TransDifferentiation of C2C12 Myoblasts. Cell Physiol Biochem (2017) 44 (6):2467-75. doi: 10.1159/000486169

63. Cinti S. Pink Adipocytes. Trends Endocrinol Metab (2018) 29(9):651-66. doi: 10.1016/j.tem.2018.05.007

64. Giordano A, Smorlesi A, Frontini A, Barbatelli G, Cinti S. White, brown and pink adipocytes: the extraordinary plasticity of the adipose organ. Eur $J$ Endocrinol / Eur Fed Endocrine Societies (2014) 170(5):R159-71. doi: 10.1530/EJE-13-0945

65. Morroni M, Giordano A, Zingaretti MC, Boiani R, De Matteis R, Kahn BB, et al. Reversible transdifferentiation of secretory epithelial cells into adipocytes in the mammary gland. Proc Natl Acad Sci USA (2004) 101 (48):16801-6. doi: 10.1073/pnas.0407647101

66. Zhang S, Cao H, Li Y, Jing Y, Liu S, Ye C, et al. Metabolic benefits of inhibition of p38alpha in white adipose tissue in obesity. PloS Biol (2018) 16 (5):e2004225. doi: 10.1371/journal.pbio.2004225

67. Vargas-Castillo A, Fuentes-Romero R, Rodriguez-Lopez LA, Torres N, Tovar AR. Understanding the Biology of Thermogenic Fat: Is Browning A New Approach to the Treatment of Obesity? Arch Med Res (2017) 48 (5):401-13. doi: 10.1016/j.arcmed.2017.10.002

68. Cypess AM, Lehman S, Williams G, Tal I, Rodman D, Goldfine AB, et al. Identification and importance of brown adipose tissue in adult humans. N Engl J Med (2009) 360(15):1509-17. doi: 10.1056/NEJMoa0810780

69. Scheele C, Nielsen S. Metabolic regulation and the anti-obesity perspectives of human brown fat. Redox Biol (2017) 12:770-5. doi: 10.1016/j.redox. 2017.04.011

70. Nedergaard J, Cannon B. The browning of white adipose tissue: some burning issues. Cell Metab (2014) 20(3):396-407. doi: 10.1016/j.cmet. 2014.07.005

71. Lowell BB, Spiegelman BM. Towards a molecular understanding of adaptive thermogenesis. Nature (2000) 404:652-60. doi: 10.1038/35007527

72. Divakaruni AS, Humphrey DM, Brand MD. Fatty acids change the conformation of uncoupling protein 1 (UCP1). J Biol Chem (2012) 287 (44):36845-53. doi: 10.1074/jbc.M112.381780

73. Fedorenko A, Lishko PV, Kirichok Y. Mechanism of fatty-acid-dependent UCP1 uncoupling in brown fat mitochondria. Cell (2012) 151(2):400-13. doi: 10.1016/j.cell.2012.09.010

74. Cannon B, Nedergaard J. Brown adipose tissue: function and physiological significance. Physiol Rev (2004) 84(1):277-359. doi: 10.1152/physrev. 00015.2003

75. Puigserver P, Wu Z, Park CW, Graves R, Wright M, Spiegelman BM. A coldinducible coactivator of nuclear receptors linked to adaptive thermogenesis. Cell (1998) 92(6):829-39. doi: 10.1016/s0092-8674(00)81410-5

76. Wu Z, Puigserver P, Andersson U, Zhang C, Adelmant G, Mootha V, et al. Mechanisms controlling mitochondrial biogenesis and respiration through the thermogenic coactivator PGC-1. Cell (1999) 98(1):115-24. doi: 10.1016/ S0092-8674(00)80611-X

77. Puigserver P, Rhee J, Lin J, Wu Z, Yoon JC, Zhang CY, et al. Cytokine stimulation of energy expenditure through p38 MAP kinase activation of PPARgamma coactivator-1. Mol Cell (2001) 8(5):971-82. doi: 10.1016/ s1097-2765(01)00390-2

78. Delghandi MP, Johannessen M, Moens U. The cAMP signalling pathway activates CREB through PKA, p38 and MSK1 in NIH 3T3 cells. Cell Signal (2005) 17(11):1343-51. doi: 10.1016/j.cellsig.2005.02.003

79. Fernandez-Marcos PJ, Auwerx J. Regulation of PGC-1alpha, a nodal regulator of mitochondrial biogenesis. Am J Clin Nutr (2011) 93(4):884S90. doi: 10.3945/ajen.110.001917

80. Zhang Y, Xie C, Wang H, Foss RM, Clare M, George EV, et al. Irisin exerts dual effects on browning and adipogenesis of human white adipocytes. Am J Physiol Endocrinol Metab (2016) 311(2):E530-41. doi: 10.1152/ajpendo. 00094.2016

81. Hondares E, Mora O, Yubero P, Rodriguez de la Concepcion M, Iglesias R, Giralt $\mathrm{M}$, et al. Thiazolidinediones and rexinoids induce peroxisome proliferator-activated receptor-coactivator (PGC)-1alpha gene transcription: an autoregulatory loop controls PGC-1alpha expression in adipocytes via peroxisome proliferator-activated receptor-gamma coactivation. Endocrinology (2006) 147(6):2829-38. doi: 10.1210/ en.2006-0070

82. Yi D, Dempersmier JM, Nguyen HP, Viscarra JA, Dinh J, Tabuchi C, et al. Zc3h10 Acts as a Transcription Factor and Is Phosphorylated to Activate the Thermogenic Program. Cell Rep (2019) 29(9):2621-33 e4. doi: 10.1016/ j.celrep.2019.10.099

83. Yau WW, Yen PM. Thermogenesis in Adipose Tissue Activated by Thyroid Hormone. Int J Mol Sci (2020) 21(8):3020. doi: 10.3390/ijms21083020

84. Ribeiro MO, Carvalho SD, Schultz JJ, Chiellini G, Scanlan TS, Bianco AC, et al. Thyroid hormone-sympathetic interaction and adaptive thermogenesis are thyroid hormone receptor isoform-specific. J Clin Invest (2001) 108 (1):97-105. doi: 10.1172/JCI12584

85. Blazquez-Medela AM, Jumabay M, Bostrom KI. Beyond the bone: Bone morphogenetic protein signaling in adipose tissue. Obesity Rev (2019) 20 (5):648-58. doi: 10.1111/obr.12822

86. Bordicchia M, Liu D, Amri EZ, Ailhaud G, Dessi-Fulgheri P, Zhang C, et al. Cardiac natriuretic peptides act via p38 MAPK to induce the brown fat thermogenic program in mouse and human adipocytes. J Clin Invest (2012) 122(3):1022-36. doi: 10.1172/JCI59701

87. Saito M, Yoneshiro T. Capsinoids and related food ingredients activating brown fat thermogenesis and reducing body fat in humans. Curr Opin Lipidol (2013) 24(1):71-7. doi: 10.1097/MOL.0b013e32835a4f40

88. Andrade JM, Frade AC, Guimaraes JB, Freitas KM, Lopes MT, Guimaraes $\mathrm{AL}$, et al. Resveratrol increases brown adipose tissue thermogenesis markers by increasing SIRT1 and energy expenditure and decreasing fat accumulation in adipose tissue of mice fed a standard diet. Eur J Nutr (2014) 53(7):1503-10. doi: 10.1007/s00394-014-0655-6

89. Ma S, Yu H, Zhao Z, Luo Z, Chen J, Ni Y, et al. Activation of the cold-sensing TRPM8 channel triggers UCP1-dependent thermogenesis and prevents obesity. J Mol Cell Biol (2012) 4(2):88-96. doi: 10.1093/jmcb/mjs001

90. Ravaud C, Pare M, Yao X, Azoulay S, Mazure NM, Dani C, et al. Resveratrol and HIV-protease inhibitors control UCP1 expression through opposite effects on p38 MAPK phosphorylation in human adipocytes. J Cell Physiol (2020) 235(2):1184-96. doi: 10.1002/jcp.29032

91. Hossain M, Imran KM, Rahman MS, Yoon D, Marimuthu V, Kim YS. Sinapic acid induces the expression of thermogenic signature genes and lipolysis through activation of PKA/CREB signaling in brown adipocytes. BMB Rep (2020) 53(3):142-7. doi: 10.5483/BMBRep.2020.53.3.093

92. Robidoux J, Cao W, Quan H, Daniel KW, Moukdar F, Bai X, et al. Selective activation of mitogen-activated protein (MAP) kinase kinase 3 and p38alpha MAP kinase is essential for cyclic AMP-dependent UCP1 expression in adipocytes. Mol Cell Biol (2005) 25(13):5466-79. doi: 10.1128/MCB.25. 13.5466-5479.2005

93. Bartelt A, Heeren J. Adipose tissue browning and metabolic health. Nat Rev Endocrinol (2014) 10(1):24-36. doi: 10.1038/nrendo.2013.204

94. Wu J, Bostrom P, Sparks LM, Ye L, Choi JH, Giang AH, et al. Beige adipocytes are a distinct type of thermogenic fat cell in mouse and human. Cell (2012) 150(2):366-76. doi: 10.1016/j.cell.2012.05.016

95. Poher AL, Altirriba J, Veyrat-Durebex C, Rohner-Jeanrenaud F. Brown adipose tissue activity as a target for the treatment of obesity/insulin resistance. Front Physiol (2015) 6:4. doi: 10.3389/fphys.2015.00004

96. Jeremic N, Chaturvedi P, Tyagi SC. Browning of White Fat: Novel Insight Into Factors, Mechanisms, and Therapeutics. J Cell Physiol (2017) 232 (1):61-8. doi: $10.1002 /$ jcp. 25450

97. Saito M, Okamatsu-Ogura Y, Matsushita M, Watanabe K, Yoneshiro T, NioKobayashi J, et al. High incidence of metabolically active brown adipose tissue in healthy adult humans: effects of cold exposure and adiposity. Diabetes (2009) 58(7):1526-31. doi: 10.2337/db09-0530

98. van Marken Lichtenbelt WD, Vanhommerig JW, Smulders NM, Drossaerts JM, Kemerink GJ, Bouvy ND, et al. Cold-activated brown adipose tissue in healthy men. N Engl J Med (2009) 360(15):1500-8. doi: 10.1056/ NEJMoa0808718

99. Young P, Arch JR, Ashwell M. Brown adipose tissue in the parametrial fat pad of the mouse. FEBS Lett (1984) 167(1):10-4. doi: 10.1016/0014-5793(84) 80822-4

100. Lee YH, Petkova AP, Mottillo EP, Granneman JG. In vivo identification of bipotential adipocyte progenitors recruited by beta3-adrenoceptor activation 
and high-fat feeding. Cell Metab (2012) 15(4):480-91. doi: 10.1016/ j.cmet.2012.03.009

101. Shen W, Chuang CC, Martinez K, Reid T, Brown JM, Xi L, et al. Conjugated linoleic acid reduces adiposity and increases markers of browning and inflammation in white adipose tissue of mice. J Lipid Res (2013) 54 (4):909-22. doi: 10.1194/jlr.M030924

102. Singh R, Braga M, Reddy ST, Lee SJ, Parveen M, Grijalva V, et al. Follistatin Targets Distinct Pathways To Promote Brown Adipocyte Characteristics in Brown and White Adipose Tissues. Endocrinology (2017) 158(5):1217-30. doi: 10.1210/en.2016-1607

103. Aartsen MG, Abbasi R, Abdou Y, Ackermann M, Adams J, Aguilar JA, et al. Evidence for high-energy extraterrestrial neutrinos at the IceCube detector. Science (2013) 342:1242856. doi: 10.1126/science.1242856

104. Sharp LZ, Shinoda K, Ohno H, Scheel DW, Tomoda E, Ruiz L, et al. Human BAT possesses molecular signatures that resemble beige/brite cells. PloS One (2012) 7(11):e49452. doi: 10.1371/journal.pone.0049452

105. Zuriaga MA, Fuster JJ, Gokce N, Walsh K. Humans and Mice Display Opposing Patterns of "Browning" Gene Expression in Visceral and Subcutaneous White Adipose Tissue Depots. Front Cardiovasc Med (2017) 4:27. doi: $10.3389 /$ fcrm.2017.00027

106. Despres JP. Body fat distribution and risk of cardiovascular disease: an update. Circulation (2012) 126(10):1301-13. doi: 10.1161/CIRCULATIONAHA. 111.067264

107. Xue B, Rim JS, Hogan JC, Coulter AA, Koza RA, Kozak LP. Genetic variability affects the development of brown adipocytes in white fat but not in interscapular brown fat. J Lipid Res (2007) 48(1):41-51. doi: 10.1194/ jlr.M600287-JLR200

108. Valle A, Garcia-Palmer FJ, Oliver J, Roca P. Sex differences in brown adipose tissue thermogenic features during caloric restriction. Cell Physiol Biochem (2007) 19(1-4):195-204. doi: 10.1159/000099207

109. Kim SN, Jung YS, Kwon HJ, Seong JK, Granneman JG, Lee YH. Sex differences in sympathetic innervation and browning of white adipose tissue of mice. Biol Sex Differ (2016) 7:67. doi: 10.1186/s13293-016-0121-7

110. Vitali A, Murano I, Zingaretti MC, Frontini A, Ricquier D, Cinti S. The adipose organ of obesity-prone C57BL/6J mice is composed of mixed white and brown adipocytes. J Lipid Res (2012) 53(4):619-29. doi: 10.1194/ jlr.M018846

111. Petrovic N, Walden TB, Shabalina IG, Timmons JA, Cannon B, Nedergaard J. Chronic peroxisome proliferator-activated receptor gamma (PPARgamma) activation of epididymally derived white adipocyte cultures reveals a population of thermogenically competent, UCP1-containing adipocytes molecularly distinct from classic brown adipocytes. J Biol Chem (2010) 285(10):7153-64. doi: 10.1074/jbc.M109.053942

112. Cinti S. Transdifferentiation properties of adipocytes in the adipose organ. Am J Physiol Endocrinol Metab (2009) 297(5):E977-86. doi: 10.1152/ ajpendo.00183.2009

113. Roh HC, Tsai LTY, Shao M, Tenen D, Shen Y, Kumari M, et al. Warming Induces Significant Reprogramming of Beige, but Not Brown, Adipocyte Cellular Identity. Cell Metab (2018) 27(5):1121-37.e5. doi: 10.1016/ j.cmet.2018.03.005

114. Elabd C, Chiellini C, Carmona M, Galitzky J, Cochet O, Petersen R, et al. Human multipotent adipose-derived stem cells differentiate into functional brown adipocytes. Stem Cells (2009) 27(11):2753-60. doi: 10.1002/stem.200

115. Jespersen NZ, Larsen TJ, Peijs L, Daugaard S, Homoe P, Loft A, et al. A classical brown adipose tissue mRNA signature partly overlaps with brite in the supraclavicular region of adult humans. Cell Metab (2013) 17(5):798805. doi: 10.1016/j.cmet.2013.04.011

116. de Jong JM, Larsson O, Cannon B, Nedergaard J. A stringent validation of mouse adipose tissue identity markers. Am J Physiol Endocrinol Metab (2015) 308(12):E1085-105. doi: 10.1152/ajpendo.00023.2015

117. Bonet ML, Oliver P, Palou A. Pharmacological and nutritional agents promoting browning of white adipose tissue. Biochim Biophys Acta (2013) 1831(5):969-85. doi: 10.1016/j.bbalip.2012.12.002

118. Cereijo R, Villarroya J, Villarroya F. Non-sympathetic control of brown adipose tissue. Int J Obes Suppl (2015) 5(Suppl 1):S40-4. doi: 10.1038/ijosup.2015.10

119. Azhar Y, Parmar A, Miller CN, Samuels JS, Rayalam S. Phytochemicals as novel agents for the induction of browning in white adipose tissue. Nutr Metab (Lond) (2016) 13:89. doi: 10.1186/s12986-016-0150-6
120. Bargut TCL, Souza-Mello V, Aguila MB, Mandarim-de-Lacerda CA. Browning of white adipose tissue: lessons from experimental models. Horm Mol Biol Clin Invest (2017) 31(1):20160051. doi: 10.1515/hmbci2016-0051

121. Hu J, Christian M. Hormonal factors in the control of the browning of white adipose tissue. Horm Mol Biol Clin Invest (2017) 31(1):20170017. doi: 10.1515/hmbci-2017-0017

122. Collins AR, Schnee J, Wang W, Kim S, Fishbein MC, Bruemmer D, et al. Osteopontin modulates angiotensin II-induced fibrosis in the intact murine heart. J Am Coll Cardiol (2004) 43(9):1698-705. doi: 10.1016/j.jacc.2003. 11.058

123. Jimenez M, Barbatelli G, Allevi R, Cinti S, Seydoux J, Giacobino JP, et al. Beta 3-adrenoceptor knockout in C57BL/6J mice depresses the occurrence of brown adipocytes in white fat. Eur J Biochem (2003) 270(4):699-705. doi: 10.1046/j.1432-1033.2003.03422.x

124. Barbatelli G, Murano I, Madsen L, Hao Q, Jimenez M, Kristiansen K, et al. The emergence of cold-induced brown adipocytes in mouse white fat depots is determined predominantly by white to brown adipocyte transdifferentiation. Am J Physiol Endocrinol Metab (2010) 298(6):E124453. doi: 10.1152/ajpendo.00600.2009

125. Park JW, Jung KH, Lee JH, Quach CH, Moon SH, Cho YS, et al. 18F-FDG PET/CT monitoring of beta3 agonist-stimulated brown adipocyte recruitment in white adipose tissue. J Nucl Med (2015) 56(1):153-8. doi: 10.2967/jnumed.114.147603

126. Chondronikola M, Volpi E, Borsheim E, Porter C, Saraf MK, Annamalai P, et al. Brown Adipose Tissue Activation Is Linked to Distinct Systemic Effects on Lipid Metabolism in Humans. Cell Metab (2016) 23(6):1200-6. doi: 10.1016/j.cmet.2016.04.029

127. Nie Y, Yan Z, Yan W, Xia Q, Zhang Y. Cold exposure stimulates lipid metabolism, induces inflammatory response in the adipose tissue of mice and promotes the osteogenic differentiation of BMMSCs via the p38 MAPK pathway in vitro. Int J Clin Exp Pathol (2015) 8(9):10875-86.

128. Sidossis LS, Porter C, Saraf MK, Borsheim E, Radhakrishnan RS, Chao T, et al. Browning of Subcutaneous White Adipose Tissue in Humans after Severe Adrenergic Stress. Cell Metab (2015) 22(2):219-27. doi: 10.1016/ j.cmet.2015.06.022

129. Xue B, Coulter A, Rim JS, Koza RA, Kozak LP. Transcriptional synergy and the regulation of Ucp1 during brown adipocyte induction in white fat depots. Mol Cell Biol (2005) 25(18):8311-22. doi: 10.1128/MCB.25.18.83118322.2005

130. Choi JH, Kim SW, Yu R, Yun JW. Monoterpene phenolic compound thymol promotes browning of 3T3-L1 adipocytes. Eur J Nutr (2017) 56(7):2329-41. doi: $10.1007 / \mathrm{s} 00394-016-1273-2$

131. Jiang J, Emont MP, Jun H, Qiao X, Liao J, Kim DI, et al. Cinnamaldehyde induces fat cell-autonomous thermogenesis and metabolic reprogramming. Metab Clin Exp (2017) 77:58-64. doi: 10.1016/j.metabol.2017.08.006

132. Choi M, Mukherjee S, Kang NH, Barkat JL, Parray HA, Yun JW. L-rhamnose induces browning in 3T3-L1 white adipocytes and activates HIB1B brown adipocytes. IUBMB Life (2018) 70(6):563-73. doi: 10.1002/iub.1750

133. Rodriguez Lanzi C, Perdicaro DJ, Landa MS, Fontana A, Antoniolli A, Miatello RM, et al. Grape pomace extract induced beige cells in white adipose tissue from rats and in 3T3-L1 adipocytes. J Nutr Biochem (2018) 56:224-33. doi: 10.1016/j.jnutbio.2018.03.001

134. Rahman MS, Kim YS. PINK1-PRKN mitophagy suppression by mangiferin promotes a brown-fat-phenotype via PKA-p38 MAPK signalling in murine C3H10T1/2 mesenchymal stem cells. Metab Clin Exp (2020) 107:154228. doi: 10.1016/j.metabol.2020.154228

135. Zhao YX, Pan JB, Wang YN, Zou Y, Guo L, Tang QQ, et al. Stimulation of histamine $\mathrm{H} 4$ receptor participates in cold-induced browning of subcutaneous white adipose tissue. Am J Physiol Endocrinol Metab (2019) 317(6):E1158-E71. doi: 10.1152/ajpendo.00131.2019

136. Collins S, Sarzani R, Bordicchia M. Coordinate control of adipose 'browning' and energy expenditure by beta-adrenergic and natriuretic peptide signalling. Int $J$ Obes Suppl (2014) 4(Suppl 1):S17-20. doi: 10.1038/ijosup.2014.6

137. Wu W, Shi F, Liu D, Ceddia RP, Gaffin R, Wei W, et al. Enhancing natriuretic peptide signaling in adipose tissue, but not in muscle, protects against diet-induced obesity and insulin resistance. Sci Signal (2017) 10 (489):1-24. doi: 10.1126/scisignal.aam6870 
138. Liu D, Bordicchia M, Zhang C, Fang H, Wei W, Li JL, et al. Activation of mTORC1 is essential for beta-adrenergic stimulation of adipose browning. J Clin Invest (2016) 126(5):1704-16. doi: 10.1172/JCI83532

139. Liu D, Ceddia RP, Collins S. Cardiac natriuretic peptides promote adipose 'browning' through mTOR complex-1. Mol Metab (2018) 9:192-8. doi: 10.1016/j.molmet.2017.12.017

140. Alvarez-Crespo M, Csikasz RI, Martinez-Sanchez N, Dieguez C, Cannon B, Nedergaard J, et al. Essential role of UCP1 modulating the central effects of thyroid hormones on energy balance. Mol Metab (2016) 5(4):271-82. doi: 10.1016/j.molmet.2016.01.008

141. Obregon MJ. Adipose tissues and thyroid hormones. Front Physiol (2014) 5:479. doi: 10.3389/fphys.2014.00479

142. Martinez-Sanchez N, Moreno-Navarrete JM, Contreras C, Rial-Pensado E, Ferno J, Nogueiras R, et al. Thyroid hormones induce browning of white fat. J Endocrinol (2017) 232(2):351-62. doi: 10.1530/JOE-16-0425

143. Lin JZ, Martagon AJ, Cimini SL, Gonzalez DD, Tinkey DW, Biter A, et al. Pharmacological Activation of Thyroid Hormone Receptors Elicits a Functional Conversion of White to Brown Fat. Cell Rep (2015) 13 (8):1528-37. doi: 10.1016/j.celrep.2015.10.022

144. Wang CZ, Wei D, Guan MP, Xue YM. Triiodothyronine regulates distribution of thyroid hormone receptors by activating AMP-activated protein kinase in 3T3-L1 adipocytes and induces uncoupling protein-1 expression. Mol Cell Biochem (2014) 393(1-2):247-54. doi: 10.1007/s11010-014-2067-6

145. Townsend LK, Wright DC. Looking on the "brite" side exercise-induced browning of white adipose tissue. Pflugers Arch (2019) 471(3):455-65. doi: 10.1007/s00424-018-2177-1

146. Irving BA, Still CD, Argyropoulos G. Does IRISIN Have a BRITE Future as a Therapeutic Agent in Humans? Curr Obes Rep (2014) 3:235-41. doi: 10.1007/s13679-014-0091-1

147. Gamas L, Matafome P, Seica R. Irisin and Myonectin Regulation in the Insulin Resistant Muscle: Implications to Adipose Tissue: Muscle Crosstalk. J Diabetes Res (2015) 2015:359159. doi: 10.1155/2015/359159

148. Grygiel-Gorniak B, Puszczewicz M. A review on irisin, a new protagonist that mediates muscle-adipose-bone-neuron connectivity. Eur Rev Med Pharmacol Sci (2017) 21(20):4687-93.

149. Bostrom P, Wu J, Jedrychowski MP, Korde A, Ye L, Lo JC, et al. A PGC1alpha-dependent myokine that drives brown-fat-like development of white fat and thermogenesis. Nature (2012) 481:463-8. doi: 10.1038/nature10777

150. Xiong XQ, Chen D, Sun HJ, Ding L, Wang JJ, Chen Q, et al. FNDC5 overexpression and irisin ameliorate glucose/lipid metabolic derangements and enhance lipolysis in obesity. Biochim Biophys Acta (2015) 1852(9):186775. doi: 10.1016/j.bbadis.2015.06.017

151. Zhang Y, Li R, Meng Y, Li S, Donelan W, Zhao Y, et al. Irisin stimulates browning of white adipocytes through mitogen-activated protein kinase p38 MAP kinase and ERK MAP kinase signaling. Diabetes (2014) 63(2):514-25. doi: $10.2337 / \mathrm{db} 13-1106$

152. Schaalan MF, Ramadan BK, Abd Elwahab AH. Synergistic effect of carnosine on browning of adipose tissue in exercised obese rats; a focus on circulating irisin levels. J Cell Physiol (2018) 233(6):5044-57. doi: 10.1002/jcp.26370

153. Elsen M, Raschke S, Tennagels N, Schwahn U, Jelenik T, Roden M, et al. BMP4 and BMP7 induce the white-to-brown transition of primary human adipose stem cells. Am J Physiol Cell Physiol (2014) 306(5):C431-40. doi: 10.1152/ajpcell.00290.2013

154. Schulz TJ, Huang TL, Tran TT, Zhang H, Townsend KL, Shadrach JL, et al. Identification of inducible brown adipocyte progenitors residing in skeletal muscle and white fat. Proc Natl Acad Sci USA (2011) 108(1):143-8. doi: 10.1073/pnas.1010929108

155. Qian SW, Tang Y, Li X, Liu Y, Zhang YY, Huang HY, et al. BMP4-mediated brown fat-like changes in white adipose tissue alter glucose and energy homeostasis. Proc Natl Acad Sci USA (2013) 110(9):E798-807. doi: 10.1073/ pnas. 1215236110

156. Gustafson B, Hammarstedt A, Hedjazifar S, Hoffmann JM, Svensson PA, Grimsby J, et al. BMP4 and BMP Antagonists Regulate Human White and Beige Adipogenesis. Diabetes (2015) 64(5):1670-81. doi: 10.2337/db141127

157. Xue R, Wan Y, Zhang S, Zhang Q, Ye H, Li Y. Role of bone morphogenetic protein 4 in the differentiation of brown fat-like adipocytes. Am J Physiol Endocrinol Metab (2014) 306(4):E363-72. doi: 10.1152/ajpendo.00119.2013
158. Zhang W, Wu X, Pei Z, Kiess W, Yang Y, Xu Y, et al. GDF5 Promotes White Adipose Tissue Thermogenesis via p38 MAPK Signaling Pathway. DNA Cell Biol (2019) 38(11):1303-12. doi: 10.1089/dna.2019.4724

159. Hua L, Zhuo Y, Jiang D, Li J, Huang X, Zhu Y, et al. Identification of hepatic fibroblast growth factor 21 as a mediator in 17beta-estradiol-induced white adipose tissue browning. FASEB J (2018) 32(10):5602-11. doi: 10.1096/ fj.201800240R

160. Lee P, Linderman JD, Smith S, Brychta RJ, Wang J, Idelson C, et al. Irisin and FGF21 are cold-induced endocrine activators of brown fat function in humans. Cell Metab (2014) 19(2):302-9. doi: 10.1016/j.cmet.2013.12.017

161. Xu X, Krumm C, So JS, Bare CJ, Holman C, Gromada J, et al. Preemptive Activation of the Integrated Stress Response Protects Mice From DietInduced Obesity and Insulin Resistance by Fibroblast Growth Factor 21 Induction. Hepatology (2018) 68(6):2167-81. doi: 10.1002/hep.30060

162. Siwaponanan P, Siegers JY, Ghazali R, Ng T, McColl B, Ng GZ, et al. Reduced PU.1 expression underlies aberrant neutrophil maturation and function in beta-thalassemia mice and patients. Blood (2017) 129(23):3087-99. doi: 10.1182/blood-2016-07-730135

163. Douris N, Stevanovic DM, Fisher FM, Cisu TI, Chee MJ, Nguyen NL, et al. Central Fibroblast Growth Factor 21 Browns White Fat via Sympathetic Action in Male Mice. Endocrinology (2015) 156(7):2470-81. doi: 10.1210/ en.2014-2001

164. Fisher FM, Kleiner S, Douris N, Fox EC, Mepani RJ, Verdeguer F, et al. FGF21 regulates PGC-1alpha and browning of white adipose tissues in adaptive thermogenesis. Genes Dev (2012) 26(3):271-81. doi: 10.1101/ gad.177857.111

165. Quesada-Lopez T, Cereijo R, Turatsinze JV, Planavila A, Cairo M, GavaldaNavarro A, et al. The lipid sensor GPR120 promotes brown fat activation and FGF21 release from adipocytes. Nat Commun (2016) 7:13479. doi: 10.1038/ ncomms 13479

166. Mercader J, Ribot J, Murano I, Felipe F, Cinti S, Bonet ML, et al. Remodeling of white adipose tissue after retinoic acid administration in mice. Endocrinology (2006) 147(11):5325-32. doi: 10.1210/en.2006-0760

167. Mercader J, Palou A, Bonet ML. Induction of uncoupling protein-1 in mouse embryonic fibroblast-derived adipocytes by retinoic acid. Obesity (Silver Spring Md) (2010) 18(4):655-62. doi: 10.1038/oby.2009.330

168. Fang S, Suh JM, Reilly SM, Yu E, Osborn O, Lackey D, et al. Intestinal FXR agonism promotes adipose tissue browning and reduces obesity and insulin resistance. Nat Med (2015) 21(2):159-65. doi: 10.1038/nm.3760

169. Elattar S, Dimri M, Satyanarayana A. The tumor secretory factor ZAG promotes white adipose tissue browning and energy wasting. FASEB J (2018) 32(9):4727-43. doi: 10.1096/fj.201701465RR

170. Xiao XH, Qi XY, Wang YD, Ran L, Yang J, Zhang HL, et al. Zinc alpha2 glycoprotein promotes browning in adipocytes. Biochem Biophys Res Commun (2018) 496(2):287-93. doi: 10.1016/j.bbrc.2018.01.039

171. Bae IS, Kim SH. Sinapic Acid Promotes Browning of 3T3-L1 Adipocytes via p38 MAPK/CREB Pathway. BioMed Res Int (2020) 2020:5753623. doi: $10.1155 / 2020 / 5753623$

172. Kang NH, Mukherjee S, Jang MH, Pham HG, Choi M, Yun JW. Ketoprofen alleviates diet-induced obesity and promotes white fat browning in mice via the activation of COX-2 through mTORC1-p38 signaling pathway. Pflugers Arch (2020) 472(5):583-96. doi: 10.1007/s00424-020-02380-7

173. Zhang Y, Proenca R, Maffei M, Barone M, Leopold L, Friedman JM. Positional cloning of the mouse obese gene and its human homologue. Nature (1994) 372:425-32. doi: 10.1038/372425a0

174. Rosen ED, Spiegelman BM. What we talk about when we talk about fat. Cell (2014) 156(1-2):20-44. doi: 10.1016/j.cell.2013.12.012

175. Fasshauer M, Bluher M. Adipokines in health and disease. Trends Pharmacol Sci (2015) 36(7):461-70. doi: 10.1016/j.tips.2015.04.014

176. Holland WL, Miller RA, Wang ZV, Sun K, Barth BM, Bui HH, et al. Receptor-mediated activation of ceramidase activity initiates the pleiotropic actions of adiponectin. Nat Med (2011) 17(1):55-63. doi: 10.1038/nm.2277

177. Hotamisligil GS, Shargill NS, Spiegelman BM. Adipose expression of tumor necrosis factor-alpha: direct role in obesity-linked insulin resistance. Science (1993) 259:87-91. doi: 10.1126/science.7678183

178. Ortega MT, Xie L, Mora S, Chapes SK. Evaluation of macrophage plasticity in brown and white adipose tissue. Cell Immunol (2011) 271(1):124-33. doi: 10.1016/j.cellimm.2011.06.012 
179. Fried SK, Bunkin DA, Greenberg AS. Omental and subcutaneous adipose tissues of obese subjects release interleukin-6: depot difference and regulation by glucocorticoid. J Clin Endocrinol Metab (1998) 83(3):847-50. doi: $10.1210 /$ jcem.83.3.4660

180. Shimobayashi M, Albert V, Woelnerhanssen B, Frei IC, Weissenberger D, Meyer-Gerspach AC, et al. Insulin resistance causes inflammation in adipose tissue. J Clin Invest (2018) 128(4):1538-50. doi: 10.1172/JCI96139

181. Takahashi K, Yamaguchi S, Shimoyama T, Seki H, Miyokawa K, Katsuta H, et al. JNK- and IkappaB-dependent pathways regulate MCP-1 but not adiponectin release from artificially hypertrophied 3T3-L1 adipocytes preloaded with palmitate in vitro. Am J Physiol Endocrinol Metab (2008) 294(5):E898-909. doi: 10.1152/ajpendo.00131.2007

182. Manieri E, Herrera-Melle L, Mora A, Tomas-Loba A, Leiva-Vega L, Fernandez DI, et al. Adiponectin accounts for gender differences in hepatocellular carcinoma incidence. J Exp Med (2019) 216(5):1108-19. doi: $10.1084 /$ jem. 20181288

183. Finck BN, Johnson RW. Anti-inflammatory agents inhibit the induction of leptin by tumor necrosis factor-alpha. Am J Physiol Regul Integr Comp Physiol (2002) 282(5):R1429-35. doi: 10.1152/ajpregu.00569.2001

184. Trujillo ME, Lee MJ, Sullivan S, Feng J, Schneider SH, Greenberg AS, et al. Tumor necrosis factor alpha and glucocorticoid synergistically increase leptin production in human adipose tissue: role for p38 mitogen-activated protein kinase. J Clin Endocrinol Metab (2006) 91(4):1484-90. doi: 10.1210/ jc.2005-1901

185. Uchiyama T, Okajima F, Mogi C, Tobo A, Tomono S, Sato K. Alamandine reduces leptin expression through the c-Src/p38 MAP kinase pathway in adipose tissue. PloS One (2017) 12(6):e0178769. doi: 10.1371/journal. pone. 0178769

186. Ge Q, Maury E, Rycken L, Gerard J, Noel L, Detry R, et al. Endocannabinoids regulate adipokine production and the immune balance of omental adipose tissue in human obesity. Int J Obes (Lond) (2013) 37(6):874-80. doi: 10.1038/ ijo. 2012.123

187. Scheja L, Heeren J. The endocrine function of adipose tissues in health and cardiometabolic disease. Nat Rev Endocrinol (2019) 15(9):507-24. doi: 10.1038/s41574-019-0230-6

188. Cereijo R, Gavalda-Navarro A, Cairo M, Quesada-Lopez T, Villarroya J, Moron-Ros S, et al. CXCL14, a Brown Adipokine that Mediates Brown-Fatto-Macrophage Communication in Thermogenic Adaptation. Cell Metab (2018) 28(5):750-63 e6. doi: 10.1016/j.cmet.2018.07.015

189. Ota T. Obesity-induced inflammation and insulin resistance. Front Endocrinol (Lausanne) (2014) 5:204. doi: 10.3389/fendo.2014.00204

190. Reilly SM, Ahmadian M, Zamarron BF, Chang L, Uhm M, Poirier B, et al. A subcutaneous adipose tissue-liver signalling axis controls hepatic gluconeogenesis. Nat Commun (2015) 6:6047. doi: 10.1038/ncomms7047

191. Knudsen JG, Murholm M, Carey AL, Bienso RS, Basse AL, Allen TL, et al. Role of IL-6 in exercise training- and cold-induced UCP1 expression in subcutaneous white adipose tissue. PloS One (2014) 9(1):e84910. doi: 10.1371/journal.pone.0084910

192. Trim W, Turner JE, Thompson D. Parallels in Immunometabolic Adipose Tissue Dysfunction with Ageing and Obesity. Front Immunol (2018) 9:169. doi: 10.3389/fimmu.2018.00169
193. Ryden M, Dicker A, van Harmelen V, Hauner H, Brunnberg M, Perbeck L, et al. Mapping of early signaling events in tumor necrosis factor-alpha -mediated lipolysis in human fat cells. J Biol Chem (2002) 277(2):1085-91. doi: 10.1074/jbc.M109498200

194. Samad F, Yamamoto K, Loskutoff DJ. Distribution and regulation of plasminogen activator inhibitor-1 in murine adipose tissue in vivo. Induction by tumor necrosis factor-alpha and lipopolysaccharide. J Clin Invest (1996) 97(1):37-46. doi: 10.1172/JCI118404

195. Pandey M, Loskutoff DJ, Samad F. Molecular mechanisms of tumor necrosis factor-alpha-mediated plasminogen activator inhibitor-1 expression in adipocytes. FASEB J (2005) 19(10):1317-9. doi: 10.1096/fj.04-3459fje

196. Mottillo EP, Shen XJ, Granneman JG. beta3-adrenergic receptor induction of adipocyte inflammation requires lipolytic activation of stress kinases p38 and JNK. Biochim Biophys Acta (2010) 1801(9):1048-55. doi: 10.1016/ j.bbalip.2010.04.012

197. Wu Y, Smas CM. Wdnm1-like, a new adipokine with a role in MMP-2 activation. Am J Physiol Endocrinol Metab (2008) 295(1):E205-15. doi: 10.1152/ajpendo.90316.2008

198. Omran F, Christian M. Inflammatory Signaling and Brown Fat Activity. Front Endocrinol (Lausanne) (2020) 11:156. doi: 10.3389/fendo.2020.00156

199. Gonzalez-Teran B, Cortes JR, Manieri E, Matesanz N, Verdugo A, Rodriguez ME, et al. Eukaryotic elongation factor 2 controls TNF-alpha translation in LPS-induced hepatitis. J Clin Invest (2013) 123(1):164-78. doi: 10.1172/ JCI65124

200. Goto T, Naknukool S, Yoshitake R, Hanafusa Y, Tokiwa S, Li Y, et al. Proinflammatory cytokine interleukin-1beta suppresses cold-induced thermogenesis in adipocytes. Cytokine (2016) 77:107-14. doi: 10.1016/ j.cyto.2015.11.001

201. Sakamoto T, Takahashi N, Sawaragi Y, Naknukool S, Yu R, Goto T, et al. Inflammation induced by RAW macrophages suppresses UCP1 mRNA induction via ERK activation in 10T1/2 adipocytes. Am J Physiol Cell Physiol (2013) 304(8):C729-38. doi: 10.1152/ajpcell.00312.2012

202. Sakamoto T, Nitta T, Maruno K, Yeh YS, Kuwata H, Tomita K, et al. Macrophage infiltration into obese adipose tissues suppresses the induction of UCP1 level in mice. Am J Physiol Endocrinol Metab (2016) 310(8):E676E87. doi: 10.1152/ajpendo.00028.2015

203. Nguyen KD, Qiu Y, Cui X, Goh YP, Mwangi J, David T, et al. Alternatively activated macrophages produce catecholamines to sustain adaptive thermogenesis. Nature (2011) 480:104-8. doi: 10.1038/nature10653

Conflict of Interest: The authors declare that the research was conducted in the absence of any commercial or financial relationships that could be construed as a potential conflict of interest.

Copyright (c) 2020 Leiva, Matesanz, Pulgarin-Alfaro, Nikolic and Sabio. This is an open-access article distributed under the terms of the Creative Commons Attribution License (CC BY). The use, distribution or reproduction in other forums is permitted, provided the original author(s) and the copyright owner(s) are credited and that the original publication in this journal is cited, in accordance with accepted academic practice. No use, distribution or reproduction is permitted which does not comply with these terms. 